\title{
Early Sensory Pathways for Detection of Fearful Conditioned Stimuli: Tectal and Thalamic Relays
}

\author{
Jeremy D. Cohen and Manuel A. Castro-Alamancos \\ Department of Neurobiology and Anatomy, Drexel University College of Medicine, Philadelphia, Pennsylvania 19129
}

\begin{abstract}
Sensory stimuli acquire significance through learning. A neutral sensory stimulus can become a fearful conditioned stimulus (CS) through conditioning. Here we report that the sensory pathways used to detect the CS depend on the conditioning paradigm. Animals trained to detect an electrical somatosensory stimulus delivered to the whisker pad in an active avoidance task were able to detect this CS and perform the task when a reversible or irreversible lesion was placed in either the somatosensory thalamus or the superior colliculus contralateral to the CS. However, simultaneous lesions of the somatosensory thalamus and superior colliculus contralateral to the CS blocked performance in the active avoidance task. In contrast, a lesion only of the somatosensory thalamus contralateral to the same CS, but not of the superior colliculus, blocked performance in a pavlovian fear conditioning task. In conclusion, during pavlovian fear conditioning, which is a situation in which the aversive outcome is not contingent on the behavior of the animal, the sensory thalamus is a critical relay for the detection of the CS. During active avoidance conditioning, a situation in which the aversive outcome is contingent on the behavior of the animal (i.e., the animal can avoid the aversive event), the sensory thalamus and the superior colliculus function as alternative routes for CS detection. Thus, even from early stages of sensory processing, the neural signals representing a CS are highly distributed in parallel and redundant sensory circuits, each of which can accomplish CS detection effectively depending on the conditioned behavior.
\end{abstract}

Key words: thalamus; superior colliculus; sensory processing; fear; classical conditioning; operant conditioning

\section{Introduction}

Through its association with other stimuli, a neutral sensory stimulus can acquire new meaning and become transformed into a conditioned stimulus (CS). In classical (pavlovian) conditioning paradigms, the CS predicts an unconditioned stimulus and motivates an appropriate response. In more complex operant conditioning paradigms, a CS signals a period during which a particular behavior will have reinforcing or punishing consequences, which increase or decrease the behavior, respectively. Thus, the likelihood of an operant behavior increases if it is contingent with the presentation of desired events (positive reinforcement) or the elimination of aversive or unpleasant events (negative reinforcement).

A typical form of learning that is thought to involve negative reinforcement is "active avoidance" (Mowrer, 1960). In this paradigm, the subject learns to avoid an aversive event by producing an appropriate behavioral response (avoidance response) during an interval (avoidance interval) signaled by the presentation of a CS. Although pavlovian fear conditioning is thought to play a role in early stages of active avoidance learning, maintenance of avoidance responses that are not species-specific responses (e.g.,

\footnotetext{
Received March 13, 2007; revised June 7, 2007; accepted June 11, 2007. We thank Yoshie Tawara-Hirata for excellent technical assistance.

Correspondence should be addressed to Dr. Manuel Castro-Alamancos, Department of Neurobiology and Anatomy, Drexel University College of Medicine, 2900 Queen Lane, Philadelphia, PA 19129. E-mail: mcastro@drexelmed.edu.

DOI:10.1523/JNEUROSCI.1124-07.2007

Copyright $\odot 2007$ Society for Neuroscience $\quad$ 0270-6474/07/277762-15\$15.00/0
}

shuttling) is considered to involve additional processes (for review, see Mineka, 1979; Bouton, 2007). Some models emphasize a role of the conditioned response in reducing the anxiety/fear state elicited by the CS (Mowrer, 1960; Rescorla and Solomon, 1967), other models consider the conditioned response a safety signal (Bolles et al., 1966; Bolles and Grossen, 1970), whereas cognitive models emphasize the development of expectancies that maintain the response (Seligman and Johnston, 1973; Mineka, 1979). Regardless of the psychological model, avoidance is normal in humans when there is impending danger. However, avoidance responses can be maladaptive, such as in anxiety disorders like phobias (e.g., avoiding air transportation) or social anxiety (e.g., avoiding social situations). Despite the obvious relevance, little is known about the neural circuitry involved in active avoidance behavior. This contrasts with the progress in the field of pavlovian fear conditioning, in which animals associate a neutral sensory stimulus with an aversive event resulting in a CS that produces a fear response in the form of immobility, potentiated startle response, elevated heart rate, or other measures (Davis, 1997; LeDoux, 2000; Maren, 2001; Fanselow and Poulos, 2005; Kim and Jung, 2006).

The first neural process for successful active avoidance or pavlovian fear conditioning is CS detection. In pavlovian fear conditioning, the CS is transmitted through the modality-specific sensory thalamus to reach emotional processing centers (i.e., amygdala), directly or through the cortex (Tischler and Davis, 1983; LeDoux et al., 1984, 1986; Iwata et al., 1986; Romanski and LeDoux, 1992; Campeau and Davis, 1995; Shi and Davis, 2001; 
Boatman and Kim, 2006). Whether this is also the case during active avoidance conditioning is unknown.

Rats readily learn to avoid an aversive stimulus by detecting a low-intensity $10 \mathrm{~Hz}$ electrical CS applied unilaterally to the whisker pad (Castro-Alamancos, 2004a). Such a stimulus (termed here WCS) enters the CNS via the trigeminal ganglion (see Fig. $1 A$ ) and travels to the trigeminal complex in the brainstem, which is composed of principal and spinal nuclei. Although somatosensory information is widely distributed from the trigeminal complex throughout the brainstem, cerebellum, and diencephalon (Waite, 2003), two main pathways ascend toward the contralateral midbrain and forebrain (see Fig. $1 A$ ). One reaches the thalamus (trigeminothalamic pathway) and the other reaches the midbrain tectum (trigeminotectal pathway). The trigeminothalamic pathway is composed of fibers that innervate the ventroposterior medial nucleus (VPM) and the medial portion of the posterior nucleus (POm) of the thalamus (Spacek and Lieberman, 1974; Feldman and Kruger, 1980; Chiaia et al., 1991; Williams et al., 1994; Veinante and Deschenes, 1999; Veinante et al., 2000). The trigeminotectal pathway is composed of fibers that have extensive terminal fields within the deeper layers of the superior colliculus (Killackey and Erzurumlu, 1981; Veazey and Severin, 1982; Huerta et al., 1983; Bruce et al., 1987; Rhoades et al., 1989; Veinante et al., 2000). The superior colliculus is a major component of ascending loops through the basal ganglia (McHaffie et al., 2005; Redgrave and Gurney, 2006) and descending projections that give rise to orienting and escape responses (Sprague and Meikle, 1965; Schneider, 1969; Sparks, 1986; Dean et al., 1989; Westby et al., 1990; Redgrave et al., 1993; Stein and Meredith, 1993). Thus, it is an early hub for sensorimotor integration that appears well suited to mediate active avoidance behaviors.

The thalamus and the superior colliculus form two major targets of ascending somatosensory information from the trigeminal complex. An obvious question is which of these two routes does a WCS travel to be detected and evoke an active avoidance response? We addressed this question by interfering with the trigeminothalamic and/or trigeminotectal pathways during WCS detection in an active avoidance task. A WCS is particularly well suited to address this question because its presentation is localized to a small part of the skin on only one side of the face, which greatly limits the neural circuits that are engaged compared with other stimuli typically used in behaving rats.

\section{Materials and Methods}

Fifty-four adult male rats (225-250 g) were used in this study and cared for in accordance with National Institutes of Health guidelines for laboratory animal welfare. All experiments were approved by the Drexel University Institutional Animal Care and Use Committee. Both Sprague Dawley $(n=36)$ and Long-Evans $(n=18)$ rats were used. None of the results presented here were dependent on the strain used and therefore the results were combined. At all times, food and water were available ad libitum. All animals were initially housed in groups of three for the first block of active avoidance training sessions. Once the animals were assigned to an experimental group, they were individually housed for the remainder of the experimental protocol.

Active avoidance training. During active avoidance training sessions, animals were placed in a standard shuttle box (Med Associates, St. Albans, VT) that consisted of two compartments separated by a partition extending up from the grid floor that the animal had to traverse to shuttle between compartments. A single training trial consisted of a $7 \mathrm{~s}$ avoidance interval followed by a $10 \mathrm{~s}$ escape interval. During the avoidance interval, a CS was presented for the duration of the interval or until the animal produced an avoidance response (conditioned response) by mov- ing to the adjacent compartment, whichever occurred first. If the animal produced an avoidance response, the CS was terminated and no escape interval was presented. However, if the animal did not produce an avoidance response, then during the escape interval, a mild scrambled electric footshock (unconditioned stimulus, $0.3-0.6 \mathrm{~mA}$ ), was delivered through the grid floor of the occupied half of the shuttle box. This mild electrical footshock motivates the animal to move readily to the adjacent compartment (escape response), at which point the footshock and CS are coterminated, ending the trial. During the intertrial interval (ITI), the animal awaited the next trial and was free to cross between compartments at will. These spontaneous responses are called intertrial crossings (ITCs). A training session consisted of 50-60 trials per day. The duration of the ITI in the avoidance task was either semirandomly determined by the computer in computer-initiated trials or determined by the investigator in investigator-initiated trials. In computer-initiated trials, the duration of the ITI was semirandomly chosen from a set of 10 values ranging from 25 to $45 \mathrm{~s}$. Investigator-initiated trials were identical to the computerinitiated trials, but the start of the trial was triggered by the experimenter to ensure that the animal was not "distracted" during the presentation of the CS. In particular, the investigator would start a trial as long as the animal was not grooming or producing an ITC and at least $15 \mathrm{~s}$ had passed since the previous trial. Unless otherwise indicated, the data shown correspond to computer-initiated trials. Investigator-initiated trials were used in all the experiments that involved tetrodotoxin (TTX) or muscimol infusion to reversibly inactivate the somatosensory thalamus or superior colliculus. The recorded variables that represent task performance are as follows: the number of avoidance responses, the latency of avoidance responses (from the CS onset), the latency of the escape responses (from the footshock onset), and the number of ITCs. Data were averaged over a block of trials (usually 50 trials). The task was controlled using MedPC software (Med Associates), and all data were saved for off-line analysis.

Two CSs engaging different sensory modalities were used: auditory and somatosensory. The auditory CS (ACS) consisted of an $8 \mathrm{kHz}, 82 \mathrm{~dB}$ tone. The somatosensory or whisker CS (WCS) consisted of a $10 \mathrm{~Hz}$ low-intensity (0.25-0.6 mA; 1-ms duration) train delivered through two wires implanted under the skin of the whisker pad (Castro-Alamancos, 2004a). The stimulus was set at an intensity that resulted in subtle movement of a few (three to five) whiskers but no elicitation of muscle twitches. Local field potential responses to electrical whisker pad stimulation have been analyzed previously and determined to be virtually identical to those elicited by whisker deflections, and, if presented repeatedly, this stimulus is completely ignored by the animals unless it is associated with an aversive event (Castro-Alamancos, 2004a).

For all animals, training began with the ACS active avoidance task. Training was conducted over three or four 50 -trial sessions (one session per day) until a high level of consistent ACS-mediated avoidance behavior was produced ( $>70 \%$ avoidance rate). Afterward, most animals were further trained in the WCS version of the active avoidance task. Before training in the WCS task, animals were subjected to unilateral implantation of a whisker pad stimulating electrode (see below). On the first day of training in the WCS task, animals were placed in the training apparatus for an acclimation session, during which the appropriate whisker pad electrical stimulus intensity was determined for each animal. The following day, animals were placed in the shuttle box and trained on the WCS active avoidance task. Training was conducted over three or four 50-trial sessions until a high level of avoidance behavior was produced ( $>70 \%$ avoidance rate). After the last session of active avoidance training, the corresponding lesions were produced as described in the surgical procedures section below. After 7-10 d of recovery, animals were retested on the active avoidance tasks. Postlesion ACS and WCS task testing were conducted over three or four 50-trial training sessions as before the lesions.

Pavlovian fear conditioning. Procedures occurred on 2 consecutive days and were similar to previously established protocols (LeDoux et al., 1984; Iwata et al., 1986; Rogan et al., 1997). On the first day (the training day), the animals were placed in a standard conditioning chamber $(42 \mathrm{~cm}$ length $\times 16 \mathrm{~cm}$ width $\times 30 \mathrm{~cm}$ height) and allowed to explore during a 5 min baseline period. This was followed by the presentation of 10 WCS- 
alone trials and 10 WCS-footshock pairing trials. The WCS-alone trials consisted of a $15 \mathrm{~s}$ WCS and $120 \mathrm{~s}$ of intertrial interval, whereas the WCS-footshock pairing trials were similar but the WCS coterminated with a $1 \mathrm{~s}$ footshock $(1 \mathrm{~mA})$. On the second day (the testing day), the animals were placed in a dissimilar conditioning chamber than on day 1 to minimize contextual conditioning and were allowed to explore during a $5 \mathrm{~min}$ baseline period. This was followed by the presentation of 10 WCS-alone trials as on day 1. We measured the amount of freezing behavior (Blanchard and Blanchard, 1969a,b; Fanselow, 1980) during the baseline period ( $5 \mathrm{~min}$ ) and during the WCS-alone trials $(150 \mathrm{~s})$ on the first and second days. The behavior of the animals was recorded on a video cassette recorder for off-line scoring.

Surgical procedures. For all recovery surgeries, animals were anesthetized with sodium pentobarbital $(50 \mathrm{mg} / \mathrm{kg}$, i.p.) and placed in a stereotaxic frame. All skin incisions and frame contacts with the skin were injected with lidocaine (2\%). Throughout the experiment, body temperature was automatically maintained constant with a heating pad (Harvard Apparatus, Holliston, MA). During recovery from surgery, animals received a dose of buprenorphine $(0.03 \mathrm{mg} / \mathrm{kg}$, i.m.) to reduce pain. Recovery from kainic acid (KA) lesions, whisker pad electrode implantation, and guide cannula implantations involved 7-10 d before retesting.

Whisker pad electrode implantation. Before training in the WCS task, an insulated stainless-steel bipolar electrode was placed in the left whisker pad subcutaneously to stimulate the whisker pad (CastroAlamancos, 2004a). Electrode pole separation was $\sim 1 \mathrm{~mm}$. The wires were normally placed around whiskers $\mathrm{C} 2-\mathrm{C} 4$. All electrodes and connectors were held in place using miniscrews and dental cement.

$K A$ lesions. Irreversible lesions were performed using a Hamilton syringe filled with $\mathrm{KA}$ solution $(10 \mu \mathrm{g} / \mu \mathrm{l}$ in saline). A craniotomy was made, and a cannula attached to the syringe was lowered into the target area (see coordinates below) and left in place for $5 \mathrm{~min}$, after which KA solution $(0.1-0.2 \mu \mathrm{l})$ was injected. The cannula was left in place for $\sim 5$ min and removed. The craniotomy was then covered with Gelfoam, the skin over the scalp was sutured, and all wounds were lathered with topical antibiotic ointment. The following coordinates were used. The auditory thalamus lesion group $(0.2 \mu \mathrm{l}$ ) had bilateral injections into (from bregma in $\mathrm{mm}$ ): anteroposterior $(\mathrm{A} / \mathrm{P}),-5.6$; mediolateral $(\mathrm{M} / \mathrm{L}), \pm 3.2$; dorsoventral $(\mathrm{D} / \mathrm{V}), 4.3$. The somatosensory thalamus lesion group $(0.2 \mu \mathrm{l})$ had an injection contralateral to the whisker pad electrode (in $\mathrm{mm}$ ): A/P, $-3.5 ; \mathrm{M} / \mathrm{L}, 2.7 ; \mathrm{D} / \mathrm{V}, 4.5$. The superior colliculus lesion group $(0.1 \mu \mathrm{l})$ had an injection contralateral to the whisker pad electrode (in $\mathrm{mm}$ ): $\mathrm{A} / \mathrm{P}$, $-6.5 ; \mathrm{M} / \mathrm{L}, 1.5 ; \mathrm{D} / \mathrm{V}, 4$. These coordinates and infusion volumes were based on histological results obtained from tests in naive animals (see below).

Reversible lesions (inactivation). In addition to using irreversible lesions, some animals were implanted with a guide cannula (Plastics One, Roanoke, VA) that allowed the infusion of drugs to reversibly inactivate the target structure. The guide cannulas were lowered over the same stereotaxic coordinates as outlined above, except that the tip was placed 1 $\mathrm{mm}$ dorsal to the intended depth. This was required to accommodate the injection cannula, which inserts into the guide cannula and extends 1 $\mathrm{mm}$ beyond it. The guide cannula was held in place by miniscrews and dental cement and was fitted with a dummy cannula. The injection cannula infused drugs into the target structure to reversibly inactivate it before performance in the task. Two drugs were used to reversibly inactivate the target structure: a voltage-gated sodium channel blocker, TTX $(10 \mu \mathrm{M})$, or a $\mathrm{GABA}_{\mathrm{A}}$-receptor agonist, muscimol $(300 \mu \mathrm{M})$. In control experiments, using urethane-anesthetized rats (see below), we measured the spread of TTX by placing an array of tungsten electrodes in neocortex (1 $\mathrm{mm}$ in depth) at regular intervals up to $4 \mathrm{~mm}$ from the infusion cannula (also placed $1 \mathrm{~mm}$ in depth). We found that, after infusion of TTX $(1 \mu \mathrm{l}, 10 \mu \mathrm{M})$, neural activity was abolished in electrodes located 1 $\mathrm{mm}$ from the cannula tip. Thus, we estimate that the diffusion radius for TTX is $1 \mathrm{~mm}$.

Before these inactivation experiments, the animals were subjected to 30 trials in the active avoidance task (using ACS or WCS) to demonstrate that they could perform the task, and then the animals were removed from the training box and held by the experimenter. The injection can- nula attached to a Hamilton syringe was lowered into the guide cannula and fastened securely. During a period of $2 \mathrm{~min}$, the drugs $(1 \mu \mathrm{l})$ were infused into the target area. The injection probe was left in place for an additional $3 \mathrm{~min}$ to ensure successful infusion within the region of interest, after which, the probe was removed and the animal was placed back in the shuttle box. After a waiting period to allow drug diffusion and reacclimation (10-15 $\mathrm{min}$ ), the animals were subjected to another 30 trials in the active avoidance task. A recovery from drug session was conducted on the following day.

Electrophysiological procedures to confirm reversible and irreversible somatosensory thalamus lesions and to measure superior colliculus responses. The extent of somatosensory thalamus KA lesions and its effective reversible inactivation with drugs (TTX and muscimol) were determined using electrophysiological procedures in each animal. At the completion of the behavioral training protocol in the WCS active avoidance task, the response evoked by the WCS stimulus was measured in the barrel cortex. This procedure was primarily aimed at determining whether the somatosensory thalamus lesions or inactivations were complete. Indeed, if the somatosensory thalamus lesions were complete, we would expect the WCS stimulation to produce no noticeable response in the barrel cortex (supplemental Fig. S1, available at www.jneurosci.org as supplemental material). Animals were anesthetized with sodium pentobarbital $(50 \mathrm{mg} /$ $\mathrm{kg}$, i.p.), and surgical procedures were as detailed above. The level of anesthesia was monitored with local field potential recordings and limb withdrawal reflexes and kept constant at approximately stage 3/III (Castro-Alamancos and Oldford, 2002). A large unilateral craniotomy was made over the barrel cortex contralateral to the whisker pad stimulating electrode. An incision was made in the dura to expose a $4 \mathrm{~mm}^{2}$ region of barrel cortex, and the cortical surface was covered with agarose gel $(7 \mathrm{mg} / \mathrm{ml})$. Using a single glass micropipette electrode $(0.5-1 \mathrm{M} \Omega$ ) filled with saline solution, a total of nine equally spaced penetrations forming a $3 \times 3$ grid (each site $1 \mathrm{~mm}$ apart) were used to record field potentials evoked by the WCS used in the active avoidance task. The center of the recording grid was as follows (from bregma in $\mathrm{mm}$ ): $\mathrm{A} / \mathrm{P}$, $-2.7 ; \mathrm{M} / \mathrm{L}, 5.0 ; \mathrm{D} / \mathrm{V}, 0.8-1.0$. At each site, 20 sweeps of evoked cortical field potential activity were collected. The electrical whisker pad stimuli consisted of either a single current pulse ( $1 \mathrm{~ms}$ duration) delivered at 0.1 $\mathrm{Hz}$ or a $1 \mathrm{~s}$ train $(10 \mathrm{~Hz}, 10$ pulses $)$ delivered at $0.1 \mathrm{~Hz}$ using the same current intensity used during training in the WCS active avoidance task. These same procedures were used to confirm the effective infusion of TTX into the somatosensory thalamus. In this case, the TTX $(1 \mu \mathrm{l}, 10 \mu \mathrm{M})$ was infused in anesthetized animals while recording barrel cortex responses to the WCS (supplemental Fig. S1C, available at www.jneurosci.org as supplemental material). TTX infusion in the somatosensory thalamus abolished barrel cortex responses evoked by the WCS in all of the animals included in the study. At the end of the recording experiments, animals had their brain removed and fixed in 10\% Formalin solution.

To measure superior colliculus responses evoked by whisker stimulation (Fig. 1), animals were anesthetized with urethane $(1.5 \mathrm{~g} / \mathrm{kg})$ as described previously (Hirata et al., 2006). A glass micropipette electrode (1-5 $\mathrm{M} \Omega$ ) filled with saline solution was inserted into the superior colliculus at approximately the following coordinates (from lambda in $\mathrm{mm}): \mathrm{A} / \mathrm{P}, 2-3$; M/L, 1.5-2.5; D/V , 4-5.5. A hand-held probe was used to deflect individual whiskers while monitoring multiunit activity with an audio monitor as the electrode was advanced. Once a response was obtained, the whiskers that produced a salient response (three to five) were selected for stimulation using a mechanical whisker stimulator that deflected them $(\sim 300 \mu \mathrm{m}, 1 \mathrm{~ms}$ duration $)$ at different frequencies. Field potentials were recorded by bandpass filtering the signal $(1-300 \mathrm{~Hz})$.

Histological procedures to confirm reversible and irreversible lesions. At the end of the experiments, all animals were given an overdose of sodium pentobarbital, and the brain was directly extracted and placed in paraformaldehyde (4\%). The brains were then sectioned in the sagittal plane using a vibratome $(100 \mu \mathrm{m})$ and processed for Nissl staining. The location of the lesions caused by KA and/or the location of the tip of the cannula used for drug infusions were reconstructed in three dimensions using Neurolucida software (MicroBrightField, Colchester, VT) by tracing the lesion (see Fig. 2) (supplemental Fig. S2, available at www. 
A

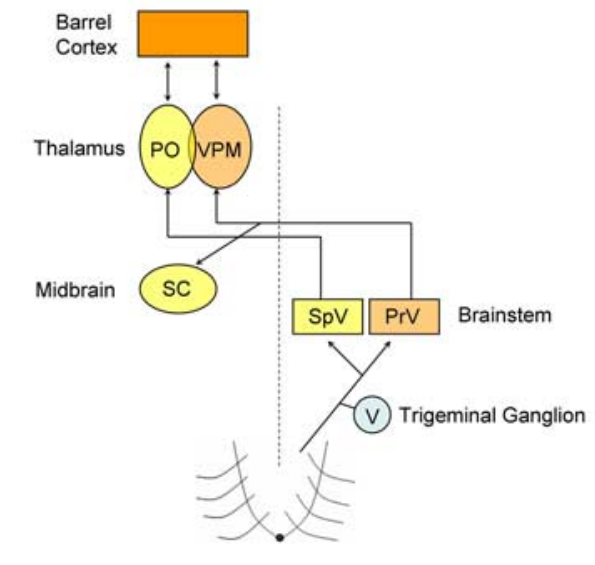

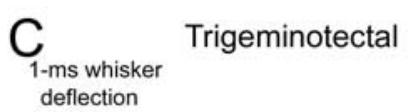

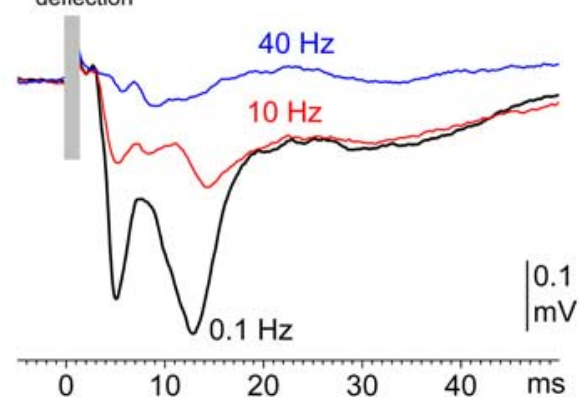

B

Trigeminothalamo-cortical

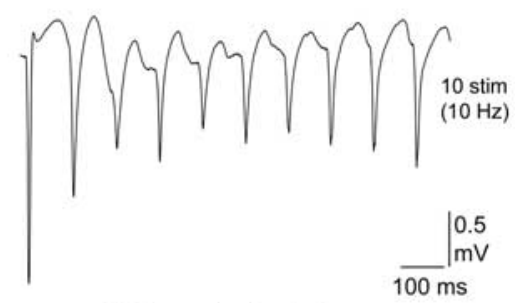

Trigeminotectal

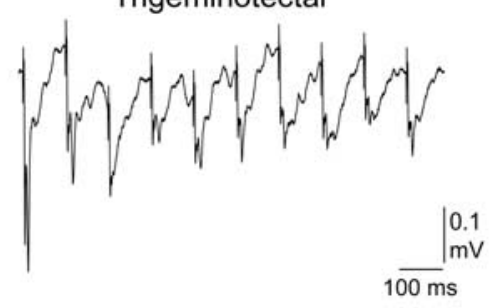

$\mathrm{D}$

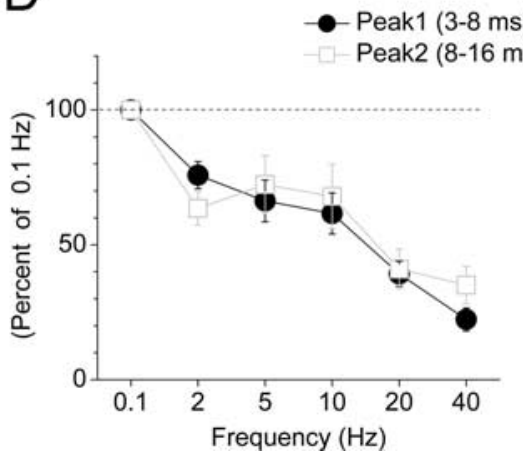

Figure 1. Ascending pathways mediating signal detection in the vibrissa system. $\boldsymbol{A}$, Schematic representation of the circuits involved in signal detection of whisker stimulation through the two main ascending and contralateral sensory pathways to the thalamus (trigeminothalamic) and to the superior colliculus (trigeminotectal). SC, Superior colliculus; SpV, spinal trigeminal nucleus; PrV, principal trigeminal nucleus; $V$, trigeminal ganglion. $\boldsymbol{B}$, Population field potential electrophysiological responses recorded in the barrel cortex (top; trigeminothalamo-cortical) and in the superior colliculus (bottom; trigeminotectal) during a train of 10 whisker deflections ( 1 ms duration, 3 whiskers) delivered at $10 \mathrm{~Hz}$ in a urethane-anesthetized rat. The traces are the average of 30 trials delivered every $10 \mathrm{~s}$. C, Close-up of field potential responses evoked in the superior colliculus by whisker stimulation (trigeminotectal) at different frequencies. The overlaid responses correspond to the 10th stimulus in a train delivered at $0.1,10$, and $40 \mathrm{~Hz}$. Note the existence of two main negative peak responses at short ( $\sim 5 \mathrm{~ms}$; peak 1$)$ and long ( $\sim 13 \mathrm{~ms}$; peak 2) latencies and also the depression of both peaks during high-frequency whisker stimulation. Traces are the average of 30 responses. $\boldsymbol{D}$, Effect of whisker stimulation frequency on the amplitude of field potential-evoked responses in the superior colliculus. Plotted is the amplitude of the short-latency ( $3-8 \mathrm{~ms}$; peak 1$)$ and the long-latency $(8-16 \mathrm{~ms}$; peak 2$)$ peak responses ( $n=7$ experiments) for the 10 th stimulus in a train.

jneurosci.org as supplemental material) or cannula tip (see Fig. 3). The lesion borders were determined by visualizing the damaged regions on Nissl sections at $20 \times$. The tracings were superimposed on a brain template generated from a normal brain cut in the same plane. This provided a threedimensional (3D) view and a measurement (volume in cubic millimeters) of the extent of the KA lesions, which allowed us to determine the structures that were impacted. In the case of drug infusions using cannulas, a volume of ink $(1 \mu \mathrm{l})$ was injected through the cannula to mark the injection site (supplemental Fig. S1, available at www.jneurosci.org as supplemental material) (see Fig. 3).

Statistics analysis. Statistical tests were done on four collected behavioral measures per session (number of avoidances, avoidance latency, escape latency, and number of ITCs). The control performance was always the last prelesion session of WCS or ACS training, which was compared with one or more postlesion sessions. To determine the effects of a particular lesion or reversible inactivation, we conducted one-factor repeated-measures ANOVAs followed by paired $t$ tests. To compare the effects of different types of lesions, we conducted two-factor repeatedmeasures ANOVAs, in which the within-subjects factor was training session (prelesion vs postlesion) and the between-subjects factor was the type of lesion or group (e.g., superior colliculus vs somatosensory thalamus). To compare the volume of lesions between groups in histological analyses, we conducted independent $t$ tests. To compare the infusion sites of cannulas between active avoidance and pavlovian fear conditioning groups, we conducted both independent $t$ tests and Mann-Whitney $U$ tests of the coordinates.

\section{Results}

\section{Histological analysis of KA lesions and} cannula injection sites

In the present study, KA was used to cause irreversible lesions of the somatosensory thalamus, superior colliculus, and auditory thalamus. In addition, guide cannulas were implanted to infuse TTX or muscimol in the somatosensory thalamus or superior colliculus and cause reversible lesions during behavior. Below we describe the criteria and results of the analyses used to verify that the irreversible lesions completely damaged the intended nuclei and were comparable between groups. Moreover, we describe the results of the analyses used to verify that the cannulas were located in the target region and that cannula placements targeting the same region were comparable between groups.

Unilateral somatosensory thalamus lesions For an animal to be included in the somatosensory thalamus reversible (TTX or muscimol infusion) or irreversible (KA) lesion group, it should meet both electrophysiology and histological criteria.

Electrophysiology verification of lesions. For the irreversible lesions, WCS electrical stimulation in urethane-anesthetized animals should produce no responses in the contralateral barrel cortex, as shown in supplemental Figure $\mathrm{S} 1 \mathrm{~A}$ (available at www.jneurosci.org as supplemental material). For reversible lesions, WCS electrical stimulation in urethane-anesthetized animals should produce normal responses in the contralateral barrel cortex (Castro-Alamancos, 2004a), but these responses should be completely abolished during infusion of TTX through the implanted cannula, as shown in supplemental Figure S1C (available at www.jneurosci.org as supplemental material). Electrophysiological verification was very useful because it clearly predicted the histological results. For example, we found that one animal subjected to a KA lesion targeting the somatosensory thalamus showed robust barrel cortex responses to the WCS during electrophysiological verification. Additional histological analysis demonstrated that the lesion had damaged POm but spared VPM. This animal could perform the active avoidance task with no impairment but was excluded from the study.

Histological verification. For irreversible lesions, subsequent histological verification of the lesion site must demonstrate complete damage of both VPM and POm, as shown in Figure 2. 
Animals with additional damage to other adjacent structures were also included (see below). For reversible lesions, a spot produced by ink infusion must be located within the vicinity of the somatosensory thalamus (VPM and POm). The location of the infusion sites for each of the animals in the study are shown in Figure 3. Note that these animals must also meet the electrophysiological criteria mentioned above.

Regarding the irreversible KA lesions in the somatosensory thalamus, it is worth noting that, in addition to complete VPM and POm damage, these animals sustained some damage to other thalamic nuclei surrounding the somatosensory thalamus. In some animals, there was also significant damage to the overlying dorsal hippocampus (data not shown). Because of concern that the unilateral hippocampus damage in animals with somatosensory thalamus lesions may be related to any of the effects in the present study, we correlated the extent (volume) of damage to the hippocampus region with behavioral performance in the WCS active avoidance task for each animal (i.e., number of avoidance responses on the last postlesion testing day). This correlation was not significant $(r=0.088$; $p=0.83 ; n=9)$, indicating that hippocampus damage caused by infusion of KA into the somatosensory thalamus had no appreciable effect on active avoidance performance. It is worth noting that some dorsal hippocampus damage was also sustained by animals with guide cannulas for reversible lesions of the somatosensory thalamus, (supplemental Fig. $\mathrm{S} 1 \mathrm{~B}$, available at www.jneurosci.org as supplemental material), and these animals also showed no appreciable impairment in active avoidance performance before drug infusions (as shown below in Fig. 5B).

To ensure that the irreversible somatosensory thalamus lesions were comparable between the different groups that sustained these lesions, we compared the damaged volume after 3D reconstructions. We found that the total damaged volume for the somatosensory thalamus lesion group of animals without $\left(29.8 \pm 5 \mathrm{~mm}^{3} ; n=4\right)$ and with $\left(32.2 \pm \mathrm{mm}^{3} ; n=5\right)$ cannulas in the superior colliculus were not significantly different $(p=0.6)$. Moreover, if only the volume of hippocampus damage is considered, there is also no significant difference between the somatosensory thalamus lesion group of animals without $\left(6.8 \pm 3 \mathrm{~mm}^{3}\right.$; $n=4)$ and with $\left(8.3 \pm 1 \mathrm{~mm}^{3} ; n=5\right)$ cannulas in the superior colliculus $(p=0.6)$. Also, the volume of hippocampus damage is on average just a small fraction $(\sim 10 \%)$ of the total hippocampus volume $\left(60.05 \mathrm{~mm}^{3}\right)$. Therefore, the extent of the thalamic and hippocampus damage between the two groups is comparable and is unlikely to explain the effects produced by subsequent superior colliculus reversible inactivation in these groups.

To ensure that the reversible somatosensory thalamus lesions were comparable between the active avoidance and the pavlovian fear conditioning groups, we compared the coordinates of the infusion sites for these two groups (Fig. 3). None of the three coordinates $(\mathrm{A} / \mathrm{P}, \mathrm{M} / \mathrm{L}$, and $\mathrm{D} / \mathrm{V})$ were significantly different $(t$ test and Mann-Whitney $U$ test; $p>0.1)$. This indicates that the location of cannula placement between the two groups are comparable and are unlikely to explain any differences produced by reversible inactivation of the somatosensory thalamus between active avoidance and pavlovian fear conditioning.

\section{Unilateral superior colliculus lesions}

For an animal to be included in the superior colliculus reversible (TTX or muscimol infusion) or irreversible (KA) lesion group, it should meet the following histological criteria. For the irreversible lesions, histological verification of the lesion site must demonstrate complete damage of all of the layers of the superior colliculus with minor damage to underlying structures, as shown in supplemental Figure S2 (available at www.jneurosci.org as supplemental material). This was important because too much damage of underlying midbrain or brainstem structures could lead to death. For reversible lesions, a spot produced by ink infusion must be located within the intermediate or deep layers of superior colliculus (Fig. 3).

To ensure that the irreversible superior colliculus lesions were comparable between the different groups that sustained these lesions, we compared the damaged volume after $3 \mathrm{D}$ reconstructions. We found that the total damaged volume for the superior colliculus lesion groups of animals without $\left(18.9 \pm 1 \mathrm{~mm}^{3} ; n=\right.$ $3)$ and with $\left(24.1 \pm 5 \mathrm{~mm}^{3} ; n=2\right)$ cannulas in the somatosensory thalamus were not significantly different $(p=0.4)$. Therefore, the extent of the superior colliculus damage is unlikely to explain the effects produced by subsequent somatosensory thalamus reversible inactivation in these groups.

To ensure that the reversible superior colliculus lesions were comparable between the active avoidance and the pavlovian fear conditioning groups, we compared the coordinates of the infusion sites for these two groups (Fig. 3). None of the three coordinates $(\mathrm{A} / \mathrm{P}, \mathrm{M} / \mathrm{L}$, and $\mathrm{D} / \mathrm{V})$ were significantly different $(p>0.1)$ This indicates that the location of cannula placement between the two groups are comparable and are unlikely to explain any differences produced by reversible inactivation of the superior col- 


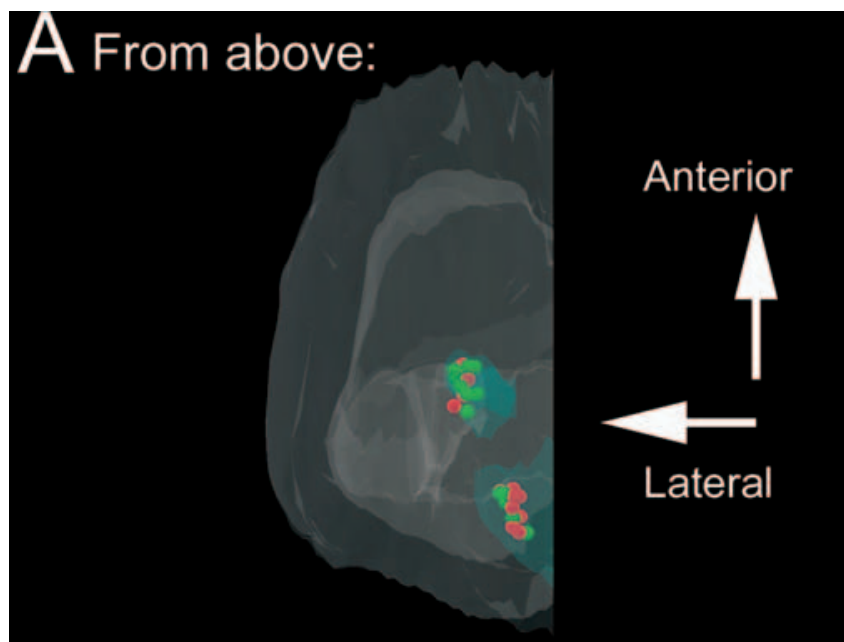

\section{From behind:}
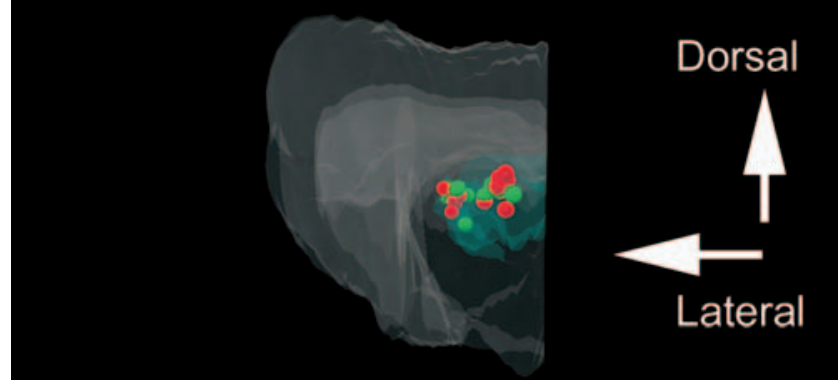

\section{From medial side:}

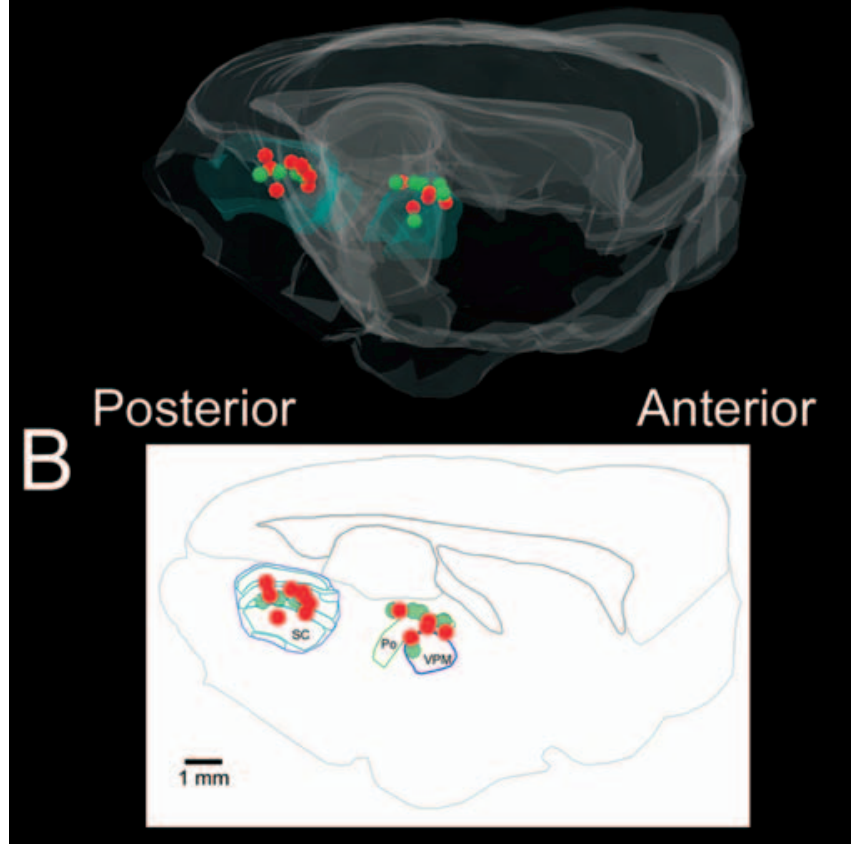

Figure 3. Reconstruction of the location of cannula infusion sites in somatosensory thalamus and superior colliculus for all animals in the study. The location was determined based on ink infusions before perfusion of the animal with fixative. $A, 3 D$ view of the location of each infusion site. The circles represent the location from where the infused drugs (TTX or muscimol) spread in each animal. The red circles correspond to the active avoidance group, and the green circles correspond to the pavlovian fear conditioning group. Three different projections are shown (from above, dorsal view; from behind, caudal view; from medial side, medial view). VPM, PO, and superior colliculus (all in transparent light blue) are shown for reference. $\boldsymbol{B}$, Sagittal plane of cannulas targeting the somatosensory thalamus and superior colliculus. All of the infusion sites are projected onto one sagittal section (i.e., 2-dimensional medial side view). The filled red circles correspond to the active avoidance group, and the open green circles correspond to the pavlovian fear conditioning group. VPM, PO, and superior colliculus are shown for reference. liculus between the active avoidance and pavlovian fear conditioning.

\section{Bilateral auditory thalamus lesions}

Animals with irreversible bilateral lesions in the auditory thalamus (medial geniculate body) sustained fairly large damage on each side (29.2 $\pm 2 \mathrm{~mm}^{3} ; n=20$ hemispheres from 10 animals). These lesions completely damaged the medial geniculate body and parts of adjoining structures, such as the hippocampus and the lateral posterior nucleus (data not shown). Note that the total volume of the medial geniculate body $\left(1.64 \mathrm{~mm}^{3}\right)$ is just a fraction of the damaged volume. Thus, the lesions easily encompassed the auditory thalamus, which was verified through visual inspection of the 3D reconstructions. As described below, despite the large damage, none of these animals showed impairment in the ACS active avoidance task.

\section{Robust whisker responses in superior colliculus}

In a group of urethane-anesthetized animals $(n=7)$, we recorded field potential (population) responses evoked in the superior colliculus by deflecting whiskers in the contralateral whisker pad. Similar to trigeminothalamic (Castro-Alamancos, 2002a,b) and trigeminothalamocortical (Castro-Alamancos, 2004a) responses recorded under the same conditions, trigeminotectal responses show rapid sensory adaptation (Fig. $1 B$ ). That is, the responses depress at frequencies above $\sim 2 \mathrm{~Hz}$. Whisker deflections $(1 \mathrm{~ms})$ at low frequency $(0.1 \mathrm{~Hz})$ produced robust trigeminotectal responses consisting of two major peaks followed by a third slower peak (Fig. 1C). The initial short-latency peak (peak 1) had an onset latency of $3.05 \pm 0.4 \mathrm{~ms}$ and peaked at $5.4 \pm 0.4 \mathrm{~ms}(n=7)$. The second peak (peak 2$)$ had a longer latency that peaked at $11.3 \pm 1.1 \mathrm{~ms}$. The third peak was much broader with less amplitude and peaked at $30.4 \pm 8 \mathrm{~ms}$. All of these response components depressed as a function of frequency of the whisker stimulation (Fig. $1 D$ ). These results indicate that, similar to the trigeminothalamic pathway, the trigeminotectal pathway may serve as a fast and robust relay of sensory inputs that can potentially mediate signal detection.

\section{Signal detection in an active avoidance task}

During an active avoidance task in a shuttle box, a CS predicts the onset of an aversive event (mild footshock) and gives the opportunity to avoid it by shuttling to the adjacent compartment during a $7 \mathrm{~s}$ avoidance interval. If the animal does not avoid, an escape interval is presented consisting of a mild scrambled footshock lasting until the animal escapes to the adjacent compartment or for a maximum of $10 \mathrm{~s}$. The avoidance or escape response is followed by a random intertrial interval (determined by a computer or by the investigator in investigator-initiated trials; see Materials and Methods) during which animals are free to move about the cage. A successful avoidance response requires animals to detect the CS. Rats readily detect either an ACS ( $8 \mathrm{kHz}$ tone) or a somatosensory WCS ( $10 \mathrm{~Hz}$ subcutaneous electrical stimulus to the whisker pad) (Castro-Alamancos, 2004a). All of the animals in this study were first trained to detect the ACS in the active avoidance task during daily sessions (50-60 trials per session). Only those animals reaching a 70\% avoidance response rate criterion by the fourth training session in the ACS task were implanted with whisker pad stimulating electrodes for subsequent training to detect the WCS in the active avoidance task. Approximately half of the animals successful in the ACS task reached criterion by the third day of training; the other half reached criterion by the fourth day. Animals not reaching avoidance criterion in the ACS task were rejected and not used further. 

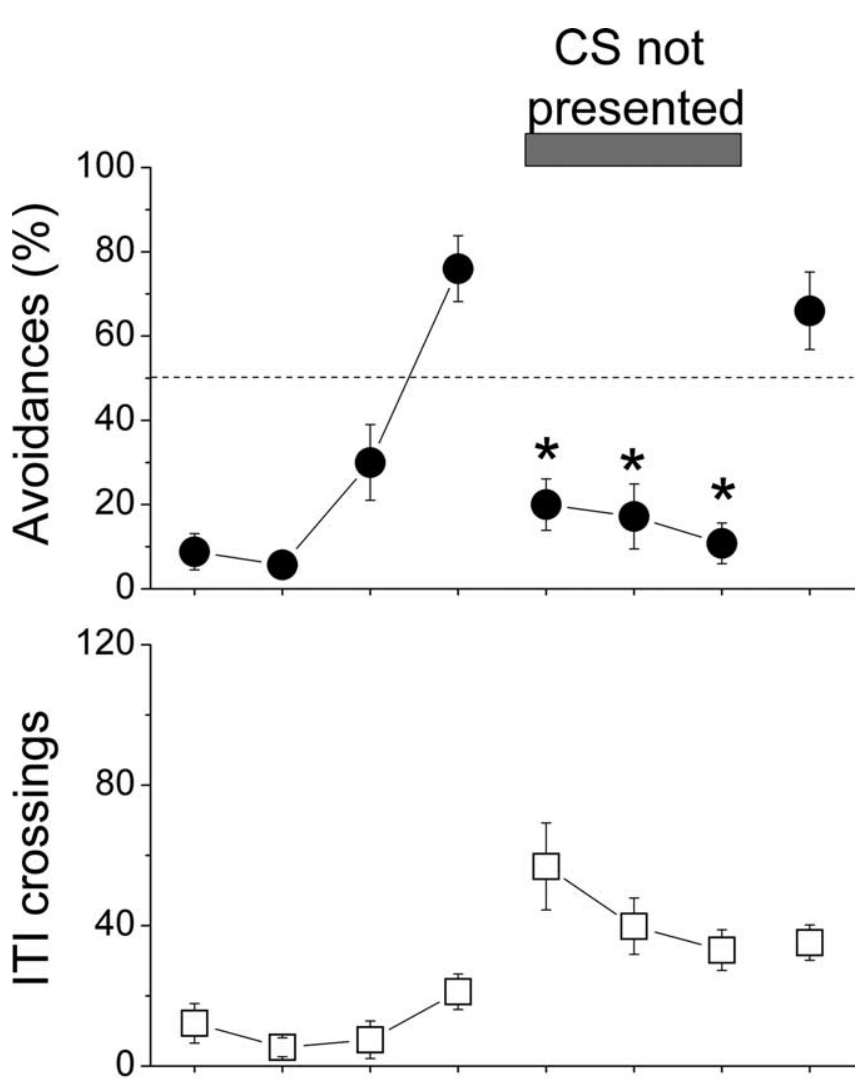

\section{Blocks of 50 trials}

Figure 4. Effect of eliminating the CS on behavioral performance in the active avoidance task in trained animals. This should be equivalent to a lesion that completely blocked detection of the CS. Percentage of avoidance responses (top) and number of intertrial interval crossings (bottom) per session (blocks of 50 trials) during performance in an ACS active avoidance task. During the three sessions marked by the gray bar, the ACS was not presented (no-CS) to determine the impact of not being able to detect the $C S$ on the active avoidance task. ${ }^{*} p<0.002$ versus fourth session with ACS present.

Because our experiments attempt to determine the neural pathways traveled by the CS so that it may be detected, we first studied the effects of eliminating the CS on behavioral performance in trained animals. In effect, this no-CS group of animals is equivalent to damaging the route traveled by the CS in the brain and completely blocking detection of the CS (i.e., an "ideal" signal detection lesion). A group of animals $(n=6)$ were trained in the ACS active avoidance task. After criterion learning was reached, the animals were subjected to three sessions in which delivery of the ACS was turned off; during the avoidance interval, in which the CS would normally be presented for $7 \mathrm{~s}$, the ACS was not presented. As shown in Figure 4, the animals were severely impaired in their ability to successfully avoid the footshock because they no longer were able to predict its onset by detecting the ACS. Thus, the avoidance rate was reduced from $76 \pm$ $1 \%$ with the ACS to $10 \pm 0.5 \%$ on the third no-CS session. Statistical analysis revealed that there was a significant effect of removing the CS on the avoidance rate $\left(F_{(4,20)}=60 ; p<\right.$ $0.001)$. This effect was attributable to a significant decrease in avoidance responses between the last ACS session and all three no-CS sessions $(p<0.002)$.

Interestingly, although there was no longer a sensory signal that predicted the onset of the footshock during the no-CS sessions, animals were able to produce a minimum number of avoidance responses by randomly shuttling during a trial (inter- trial interval crossings). This is highlighted by the relatively large number of avoidance responses (20\%) produced by chance on the first no-CS session. Such levels of avoidances were associated with a significant increase in the number of spontaneous ITCs caused by removing the ACS $\left(F_{(4,20)}=7.18 ; p=0.002\right)$. These results indicate that, when animals are incapable of detecting the CS that signals the avoidance interval and predicts the footshock, they attempt to compensate by increasing their number of ITCs. This compensatory behavior only results in relatively few spurious avoidances on the first session $(\sim 20 \%)$ and even fewer on successive sessions.

After three no-CS sessions, animals were retested on the ACS task with the ACS present. In the presence of the ACS, animals readily increased their avoidance rates. Statistical analysis revealed no significant difference in avoidance rates and avoidance latencies compared with the previous session when the ACS was present. These results indicate that being unable to detect the CS eliminates the animal's ability to avoid the footshock (only a few random avoidances occurred related to high levels of ITCs) and animals rapidly regain normal avoidance rates and latencies when they are allowed to detect the CS again.

\section{Effect of somatosensory thalamus lesions on CS detection}

A reasonable assumption is that, to detect a somatosensory CS, such as a WCS, and produce an avoidance response, the neural activity produced by the WCS must travel via the trigeminothalamic pathway to the thalamus from where it is relayed to appropriate sensorimotor and higher-order processing centers. If this is the case, then a lesion of the somatosensory thalamus should abolish the ability to detect the WCS in the active avoidance task. To test this possibility, a group of animals $(n=13)$ were trained in the ACS and WCS versions of the active avoidance task and then subjected to unilateral KA lesions of the somatosensory thalamus contralateral to the WCS. The extent of somatosensory thalamus lesions was determined using electrophysiological and histological procedures as reported in Materials and Methods (Fig. 2) (supplemental Fig. S1, available at www.jneurosci.org as supplemental material). After a 1 week recovery period, animals were retested on the WCS task for four sessions and later on the ACS task for one session. Remarkably, as shown in Figure $5 A$, animals had little impairments in the WCS task after a somatosensory thalamus lesion. The avoidance rate on the first postlesion session was $56 \pm 1 \%$, but this increased to $73.5 \pm 1 \%$ on the third postlesion session, which was similar to $74.8 \pm 0.7 \%$ before lesion. Thus, there was a significant effect of somatosensory thalamus lesion in the WCS task on avoidance rate $\left(F_{(4,48)}=6.615\right.$; $p<0.001)$, avoidance latency $\left(F_{(4,48)}=3.938 ; p=0.008\right)$, and number of ITCs $\left(F_{(4,48)}=5.263 ; p=0.001\right)$. The effect on avoidance rate was attributable to a significant decrease in avoidance responses between the last prelesion session (control) and the first ( $p=0.002$ ) and second ( $p=0.018$ ) but not the third postlesion sessions in the WCS task. In addition, there was a significant improvement between the first and the third postlesion sessions in avoidance rates $(p=0.005)$. The effect on avoidance latency was attributable to a significant $(p<0.01)$ decrease in avoidance latency only on the third training session compared with all other sessions before and after the lesion. Finally, animals with somatosensory thalamus lesions contralateral to the WCS were later tested in the ACS avoidance task and showed no deficit in this version of the task compared with prelesion values $(p=0.17)$. These results indicate that a lesion of the somatosensory thalamus contralateral to the WCS had only an initial significant effect 


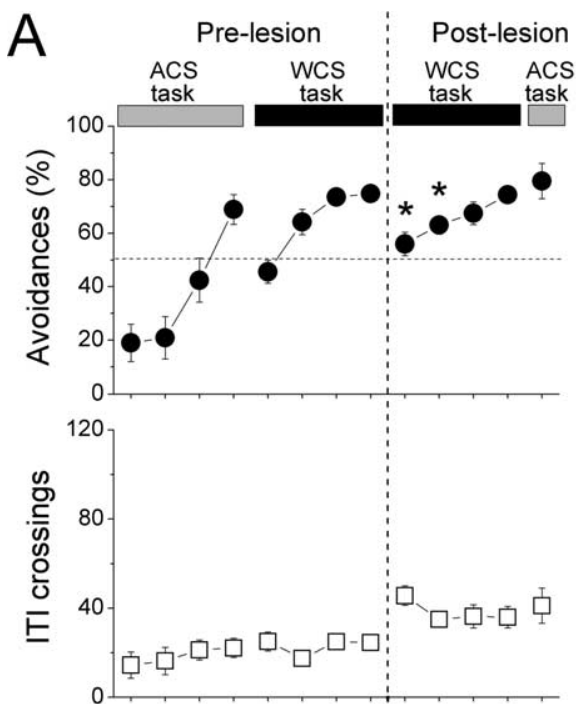

Blocks of 50 trials

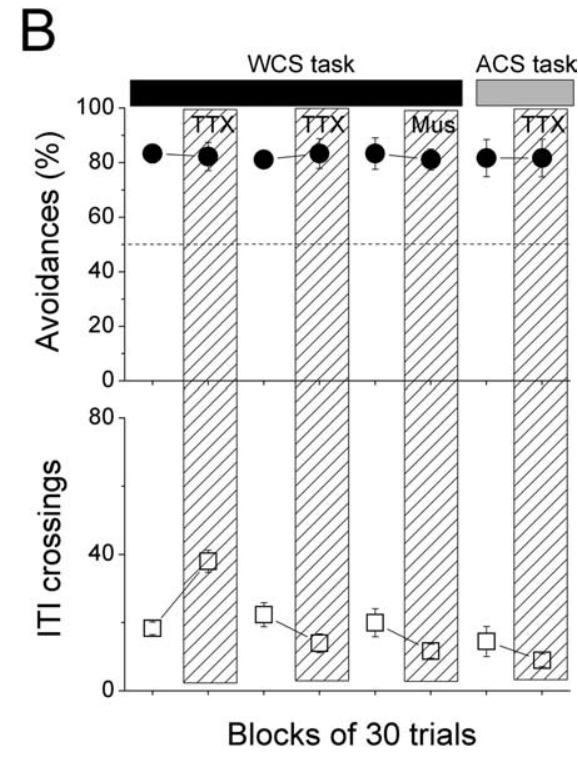

Figure 5. Effect of somatosensory thalamus lesions on WCS detection in the active avoidance task. $\boldsymbol{A}$, Effect of somatosensory thalamus KA lesions on WCS and ACS signal detection in an active avoidance task. Percentage of avoidance responses (top) and number of intertrial interval crossings (bottom) per session (blocks of 50 trials) during performance in the active avoidance task using whisker pad stimulation as a CS (WCS task) or auditory stimulation as a CS (ACS task). ${ }^{*} p<0.01$ versus last prelesion session. $\boldsymbol{B}$, Effect of somatosensory thalamus reversible inactivation with TTX or muscimol (Mus) on WCS and ACS signal detection in the active avoidance task. Four sessions are shown corresponding to 4 consecutive days. In each session, trained animals were first subjected to 30 trials under normal conditions and then infused with TTX (sessions 1, 2, and 4) or muscimol (session 3) and subjected to another 30 trials (marked by a vertical column).

on the ability of the animals to detect the WCS, which recovered rapidly after the first postlesion session.

Visual observation of the animals with thalamic lesions revealed increased hyperactivity, grooming, and exploration. Hyperactivity was observed in all animals that sustained thalamic lesions, including those with auditory thalamus lesions discussed below, and may explain the increased ITCs generally observed in these animals in the absence of deficits to detect the WCS. The increased grooming of the face and exploratory behavior (e.g., active whisking) after the somatosensory thalamus lesion could explain the initial deficit in WCS detection on the first postlesion session. To potentially overcome the secondary effects of KA lesions, in a group of animals $(n=3)$, we implanted a cannula in the somatosensory thalamus contralateral to the WCS in animals trained in the WCS and ACS tasks. Moreover, in these experiments, all of the trials were investigator initiated to ensure that the animal was not "distracted" by behaviors that increase after thalamic lesions and may interfere with CS detection (e.g., grooming of the face). These inactivation experiments consisted of four sessions on sequential days. In each session, trained animals were first subjected to 30 trials under normal conditions and then infused with TTX (sessions 1,2, and 4) or muscimol (session 3 ) and subjected to another 30 trials. Successful inactivation of the somatosensory thalamus was confirmed using electrophysiological and histological procedures as reported in Materials and Methods

(supplemental Fig. S1 $B, C$, available at www.jneurosci.org as supplemental material). Figure $5 B$ shows the effect of inactivating the somatosensory thalamus contralateral to the WCS with TTX (1 $\mu \mathrm{l} ; 10 \mu \mathrm{M})$ or muscimol $(1 \mu \mathrm{l} ; 300 \mu \mathrm{M})$. Animals had no impairments in detecting the WCS or ACS during somatosensory thalamus inactivation. For statistical analysis, the results of TTX and muscimol were combined because they were not significantly different. There was no effect of somatosensory thalamus inactivation in the WCS task (Fig. $5 B)$ on avoidance rate $\left(F_{(1,8)}=\right.$ $0.036 ; p=0.855)$, avoidance latency $\left(F_{(1,8)}=\right.$ $2.495 ; p=0.153)$, or number of ITCs $\left(F_{(1,8)}\right.$ $=0.011 ; p=0.921)$. There was also no effect of somatosensory thalamus inactivation on performance in the ACS task (Fig. 5B). Moreover, these animals showed little signs of increased grooming and hyperactivity, suggesting that these are secondary effects caused by the KA lesions. These results indicate that the most likely cause of the deficit in WCS detection on the first postlesion session in animals with KA lesions of the somatosensory thalamus is the increased face grooming, hyperactivity, and active exploration, which may interfere with WCS signal detection.

The surprising finding of only an initial and small deficit in WCS detection during performance in the active avoidance task after KA lesions and no deficit during reversible inactivation of somatosensory thalamus led us to test the effects of auditory thalamus lesions on ACS detection. If the somatosensory thalamus is not required for detecting the WCS, then the auditory thalamus would be expected not to be required for detecting the ACS. Thus, a group of animals $(n=10)$ were trained in the ACS active avoidance task and were then subjected to bilateral KA lesions of the auditory thalamus. The extent of auditory thalamus lesions was determined using histological procedures as reported in Materials and Methods. After a 1 week recovery period, animals were retested on the ACS task for three sessions. Remarkably, as shown in Figure 6, animals had no impairments in the ACS task after bilateral auditory thalamus lesions. The avoidance rate on the last prelesion session was $75.8 \pm 1 \%$, and this rate was $86 \pm 1 \%$ on the first postlesion session. In fact, there was a significant effect of auditory thalamus lesion in the ACS task on avoidance rate $\left(F_{(3,27)}=3.992 ; p=0.018\right)$, avoidance latency $\left(F_{(3,27)}=4.170 ; p=0.015\right)$, and number of ITCs $\left(F_{(3,27)}\right.$ $=21.302 ; p<0.001)$. The effect on avoidance rate was attributable to a significant increase in avoidance responses between the last prelesion session (control) and the first $(p=0.026)$ and the second $(p=0.049)$ but not the third $(p=0.086)$ postlesion session in the WCS task. The effect on avoidance latency was attributable to a significant decrease in avoidance latency between the last prelesion session (control) and the first ( $p=$ 0.024 ) postlesion session but not with the other sessions. These results demonstrate that the modality-specific sensory thalamus is not required for detection of a WCS or ACS that signals the immediate onset of an avoidable aversive event.

\section{Effect of superior colliculus lesions on CS detection}

The previous results indicate that lesions of the modality-specific sensory thalamus have little effect on the ability of the animals to detect the CS, indicating that information flow through the trigeminothalamic pathway is not necessary for WCS detection. Possibly, sensory information flow for WCS detection involves the trigeminotectal pathway. To test this hypothesis, a group of animals $(n=6)$ were trained in the ACS and WCS versions of the active avoidance task and then subjected to unilateral KA lesions of the superior colliculus contralateral to the WCS. The extent of 


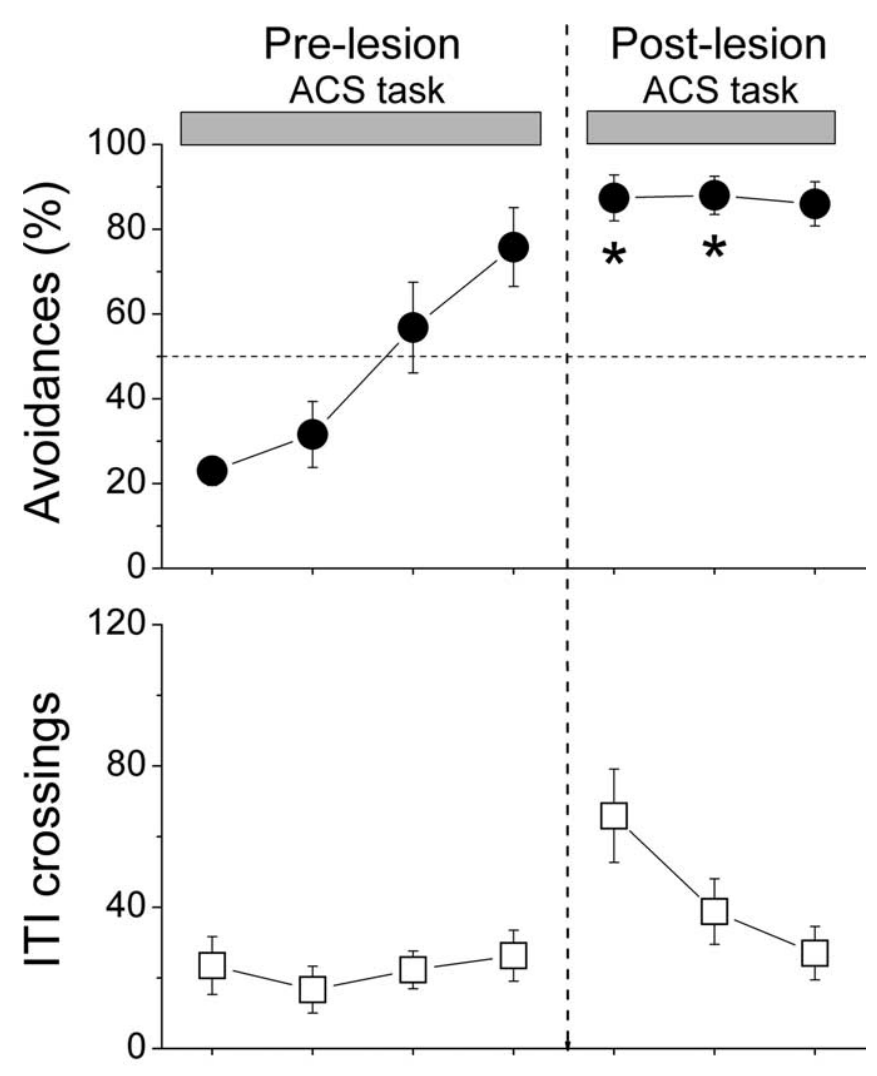

\section{Blocks of 50 trials}

Figure 6. Effect of auditory thalamus lesions on ACS detection in the active avoidance task. Percentage of avoidance responses (top) and number of intertrial interval crossings (bottom) per session (blocks of 50 trials) during performance in the active avoidance task using auditory stimulation as a CS (ACS task). ${ }^{*} p<0.05$ versus last prelesion session.

superior colliculus lesions was determined using histological procedures as reported in Materials and Methods (supplemental Fig. S2, available at www.jneurosci.org as supplemental material). After a 1 week recovery period, animals were retested on the WCS task for three sessions and later on the ACS task for one session. As shown in Figure 7A, animals had no impairments in the WCS task after a superior colliculus lesion. Thus, there was no significant effect of superior colliculus lesion on avoidance rate $\left(F_{(3,15)}\right.$ $=2.119 ; p=0.141)$ and avoidance latency $\left(F_{(3,15)}=0.321 ; p=\right.$ $0.810)$ in the WCS task. There was also no significant effect of superior colliculus lesion on performance in the ACS task ( $p=$ 0.54 ) (Fig. 7A). These results were also confirmed in two animals with cannulas implanted in the superior colliculus contralateral to the WCS using investigator-initiated trials. In those animals, inactivation of the superior colliculus with TTX or muscimol had no significant effects on either the WCS or ACS tasks (Fig. 6B). Moreover, in five animals, we made bilateral lesions of the superior colliculus and found no significant deficits on either the WCS or ACS tasks (data not shown). These results demonstrate that the trigeminotectal pathway is not required for detection of a WCS or ACS that signals the immediate onset of an avoidable aversive event.

Although animals with either a somatosensory thalamus lesion or a superior colliculus lesion contralateral to the WCS were able to detect the WCS and perform the avoidance task, we wanted to determine whether there were any significant differences between these two groups in performance. Thus, we compared the avoidance rates and avoidance latencies of animals with superior colliculus versus somatosensory thalamus lesions contralateral to the WCS. This comparison was done on the last (third) session of postlesion training so that we would be comparing the animals at their steady-state performance capacity. Interestingly, there were no significant difference in avoidance rates (unpaired $t$ test; $p=0.16$ ), but there were significant differences in avoidance latency (unpaired $t$ test; $p=0.003$ ). The difference in latency was attributable to the fact that the somatosensory thalamus lesion group $(2.36 \pm 0.3 \mathrm{~s})$ had significantly faster avoidance latencies than the superior colliculus lesion group $(2.98 \pm 0.3 \mathrm{~s})$. Thus, this indicates that, although both groups of animals are capable of detecting the WCS, the animals with an intact trigeminotectal pathway are faster at detecting the WCS. If these pathways are compensating for each other, it could be argued that animals detect the WCS faster (i.e., have shorter reaction times) through their trigeminotectal pathway than through their trigeminothalamic pathway.

\section{Effect of dual somatosensory thalamus and superior colliculus lesions on CS detection}

The previous results indicate that neither the trigeminothalamic nor the trigeminotectal pathways alone are required for WCS detection. It is possible that the absence of one pathway is compensated by the other pathway, i.e., that they are alternative pathways for CS detection. To test this possibility, a group of animals $(n=6)$ were trained in the ACS and WCS versions of the active avoidance task and then subjected to unilateral KA lesions of the superior colliculus and somatosensory thalamus contralateral to the WCS (termed dual lesions, for simplicity). Lesions were confirmed using electrophysiological and histological procedures as described in Materials and Methods. After a 1 week recovery period, animals were retested on the WCS task for three sessions and later on the ACS task for one session. As shown in Figure $8 \mathrm{~A}$, performance on the WCS task was strongly reduced as a consequence of dual lesions. The avoidance rate on the first postlesion session was $32.7 \pm 1 \%$, and this rate was further reduced to $22.3 \pm 1.4 \%$ by the third postlesion session compared with $77.0 \pm 0.8 \%$ before the lesions. Thus, there was a significant effect of dual lesions on the avoidance rate $\left(F_{(3,15)}=36.361 ; p<0.001\right)$. This effect was attributable to a significant decrease in avoidance responses between the last prelesion session (control) and all of the postlesion sessions in the WCS task $(p<0.002)$. In addition, there were no significant differences between the three postlesion sessions, indicating that no improvement in task performance occurred with additional training after the dual lesions.

It is interesting to note that, although avoidance behavior was severely impaired, dual-lesion animals were able to maintain a minimal level of avoidance responses. This is likely attributable to the fact that the dual-lesion animals showed a large increase in the number of ITCs, which is highlighted by an almost fourfold increase on the first postlesion session (366\%). Indeed, there was a significant effect of dual lesions on ITCs $\left(F_{(3,15)}=9.881 ; p=\right.$ $0.001)$. This effect was attributable to a significant increase in ITCs for all of the postlesion sessions in the WCS task $(p<0.01)$. In addition, there was a significant decrease in ITCs between the first and third postlesion sessions $(p=0.03)$, indicating that animals stopped attempting to avoid the footshock by shuttling back and forth. Importantly, the effects of dual lesions on ITCs and avoidances are reminiscent of the no-CS training sessions (Fig. 4). Both the dual-lesion and the no-CS groups showed a severe impairment in avoidance responses but produced a correspondingly large increase in ITCs. A two-factor repeatedmeasures ANOVA comparing effect of treatment (no-CS vs dual- 

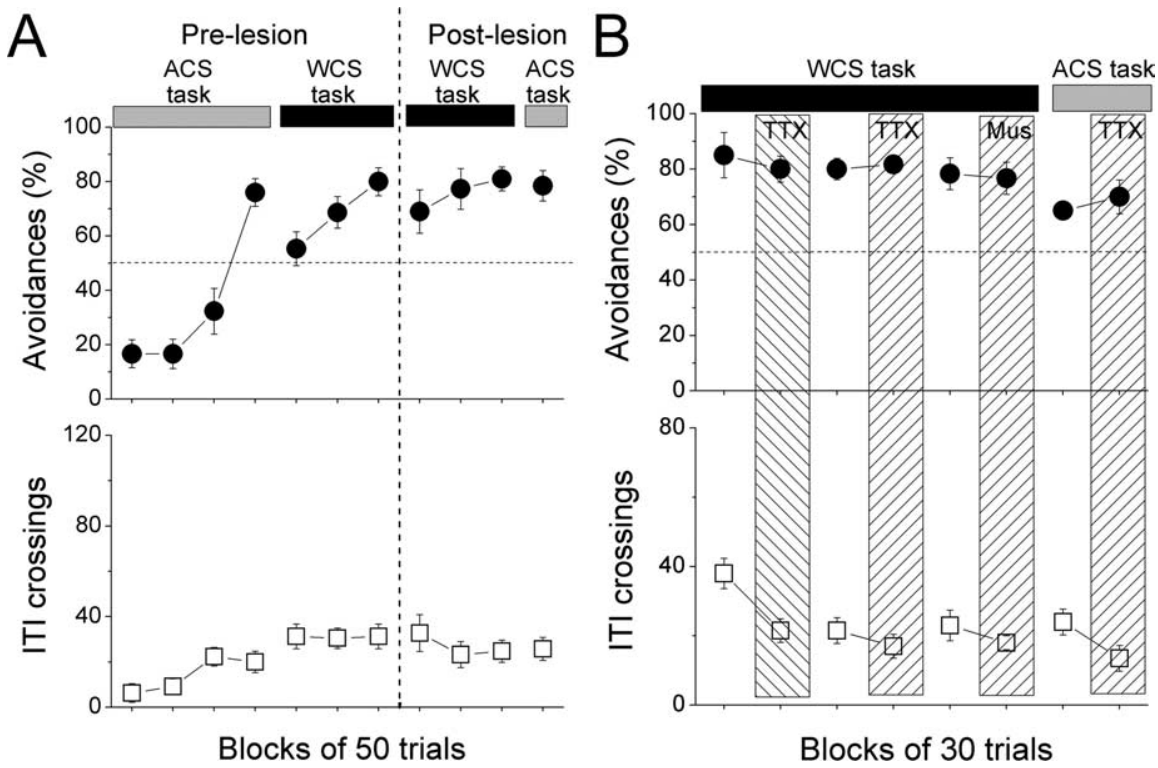

Figure 7. Effect of superior colliculus lesions on WCS detection in the active avoidance task. $A$, Effect of superior colliculus KA lesions on WCS and ACS signal detection in an active avoidance task. Percentage of avoidance responses (top) and number of intertrial interval crossings (bottom) per session (blocks of 50 trials) during performance in the active avoidance task using whisker pad stimulation as a CS (WCS task) or auditory stimulation as a CS (ACS task). B, Effect of superior colliculus reversible inactivation with TTX or muscimol (Mus) on WCS and ACS signal detection in the active avoidance task. Four sessions are shown corresponding to 4 consecutive days. In each session, trained animals were first subjected to 30 trials under normal conditions and then infused with TTX (sessions 1, 2, and 4) or muscimol (session 3) and subjected to another 30 trials (marked by a vertical column).
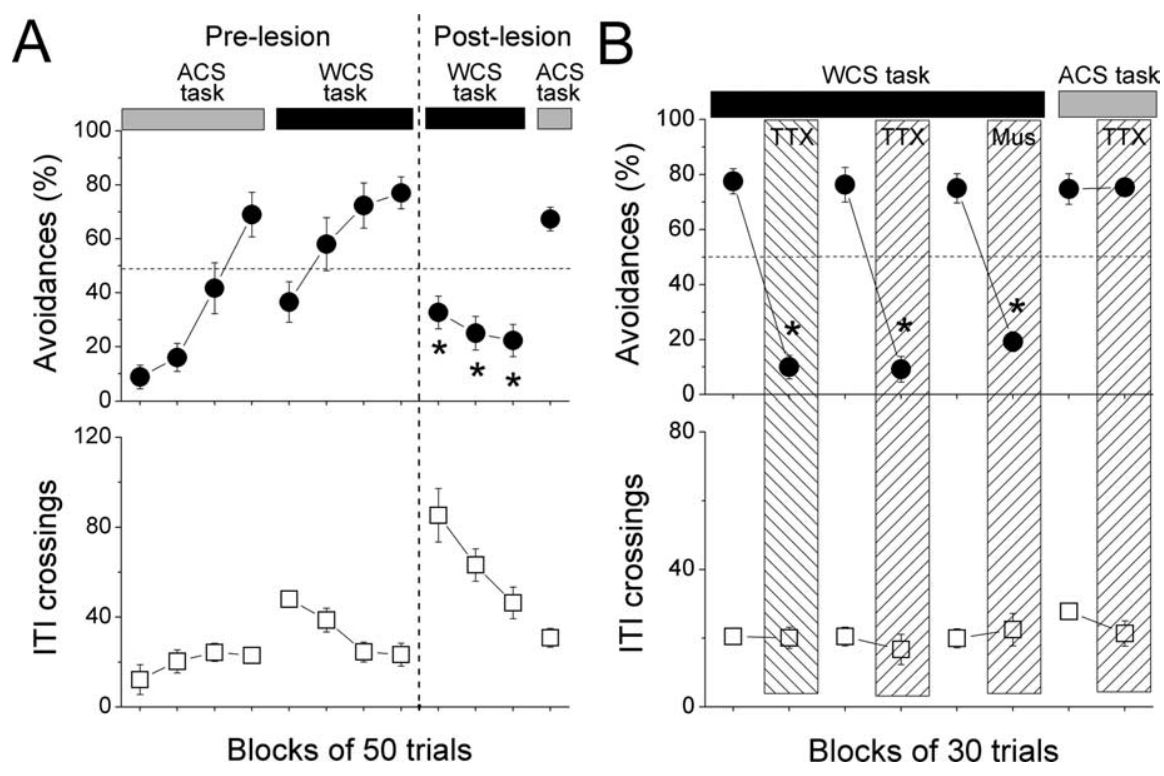

Figure 8. Effect of (dual) somatosensory thalamus and superior colliculus lesions on WCS detection in the active avoidance task. $\boldsymbol{A}$, Effect of dual KA lesions on WCS and ACS signal detection in an active avoidance task. Percentage of avoidance responses (top) and number of intertrial interval crossings (bottom) per session (blocks of 50 trials) during performance in the active avoidance task using whisker pad stimulation as a CS (WCS task) or auditory stimulation as a CS (ACS task). * $p<0.002$ versus last prelesion session). $\boldsymbol{B}$, Effect of dual lesions consisting of a KA lesion in one structure and reversible inactivation with TTX or muscimol (Mus) in the other structure on WCS and ACS signal detection in the active avoidance task. Four sessions are shown corresponding to 4 consecutive days. In each session, trained animals were first subjected to 30 trials under normal conditions and then infused with TTX (sessions 1, 2, and 4) or muscimol (session 3) and subjected to another 30 trials (marked by a vertical column). ${ }^{*} p<0.001$ versus preinfusion.

lesion) on avoidance rate revealed a significant effect of treatment $\left(F_{(1,10)}=90.655 ; p<0.001\right)$ but no effect of group $(p=0.115)$ and no interaction effect $(p=0.294)$. These results indicate that, although task performance (avoidance rate) was significantly re- duced in both groups after the dual lesion or turning off the CS, the two groups did not differ from each other. Moreover, the same analysis on ITCs revealed a significant effect of treatment $\left(F_{(1,10)}=19.355\right.$; $p=0.001)$ but no effect of group $(p=$ $0.128)$ and no interaction effect $(p=$ $0.263)$. Therefore, although the treatment (i.e., eliminating the CS or a dual lesion) increased the number of ITCs in both groups, both groups did not differ between each other in ITCs. In conclusion, a dual lesion of the superior colliculus and somatosensory thalamus contralateral to the WCS is equivalent to turning off the WCS in the avoidance task.

To further ensure that the deficits observed after dual lesions were indeed caused by the inability of the animals to detect the WCS and not attributable to other nonspecific effects, we conducted three additional analyses. First, to control for potentially confounding motor behaviors, a block of investigator-initiated trials was collected immediately after the last prelesion WCS session and after the last postlesion WCS session in the dual-lesion group. This protocol, in effect, removes spurious avoidances attributable to well timed ITCs, as well as the potential for motor behaviors that could interfere with WCS detection (e.g., face grooming). Using this method of trial activation, duallesion animals went from a $93.3 \pm 0.8 \%$ prelesion avoidance rate to a $6.7 \pm 0.8 \%$ postlesion avoidance rate, which was significantly different $(p<0.001)$.

Second, because of the minimal amount of avoidance responses produced during the 50-trial training sessions, animals in the impaired groups (no-CS and dual-lesion) were forced to escape the footshock on most trials. If the unilateral dual lesions had led to a deficit in overall somatosensation (e.g., resulting in a less salient footshock), an effect should be detectable in the latency to escape the footshock. In this case, the dual-lesion group would show longer escape latencies than the no-CS group, which has no lesion but an equivalent number of escape responses. To this extent, a two-factor repeatedmeasures ANOVA comparing escape latencies over the three postlesion or no-CS training sessions between the dual-lesion and no-CS groups revealed no significant effects. This indicates that there was no deficit in the ability of the dual-lesion animals to escape the footshock compared

with intact animals.

Finally, to ensure that the reduction in avoidance behavior produced by the dual lesion was attributable to the inability of the animals to detect the modality-specific WCS and not related to 
other sensory, cognitive, or motor deficits, all the dual-lesion animals were retested on their ability to detect the ACS in the avoidance task (Fig. 8). If the impairment is modality specific and thus confined to the WCS, these animals should have no impairment in detecting the ACS. Indeed, animals in the dual-lesion group performed the ACS task at prelesion avoidance rates $(69 \pm$ $0.4 \%$ prelesion vs $67.3 \pm 0.6 \%$ postlesion; $p=0.4$ ). Therefore, dual lesions of somatosensory thalamus and superior colliculus contralateral to the WCS selectively abolished detection of the WCS and not of the ACS.

\section{Effect of combined lesion and reversible inactivation of superior colliculus and somatosensory thalamus on CS detection}

The previous results indicate that the trigeminothalamic and trigeminotectal pathways are alternative routes for signal detection during active avoidance. However, it is conceivable that, during the extended recovery period after the dual KA lesions, there was a reorganization of relevant structures, which indirectly led to deficits in the ability to detect the CS. To prevent these potential indirect effects, a group of animals $(n=8)$ were trained in the ACS and WCS versions of the active avoidance task and then subjected to unilateral and single KA lesions of either the superior colliculus $(n=3)$ or somatosensory thalamus $(n=5)$ contralateral to the WCS (the two groups were later combined into one group because results were not different; $n=8$ ). These animals were also implanted with a guide cannula in the alternative nonlesioned superior colliculus or somatosensory thalamus contralateral to the WCS, so that the "alternative pathway" could be inactivated during performance in the task. After a 1 week recovery period from the single unilateral lesions, animals were retested on the WCS task for three sessions to ensure that they could perform the avoidance task. After that, TTX or muscimol was infused in the alternative pathway to test whether it would immediately block performance. These experiments were conducted in four sessions, the same way as described above for other inactivation experiments using investigator-initiated trials. As shown in Figure $8 B$, performance on the WCS task was strongly and significantly reduced from $76.3 \pm 0.6$ to $12.8 \pm 1.3 \%$ avoidance rates after inactivating the alternative pathway (TTX and muscimol results were combined for statistical analysis; $p<0.001$ ), which effectively produces a dual lesion of somatosensory thalamus and superior colliculus. Moreover, infusion of TTX had no effect on the ability of the animals to detect the ACS $(p=0.82)$. These results demonstrate that the trigeminothalamic and trigeminotectal pathways are alternatives for WCS signal detection during active avoidance. If either of these alternative pathways is intact, animals can effectively detect a WCS and take appropriate action.

\section{Effect of reversible inactivation of the somatosensory thalamus or superior colliculus on pavlovian fear conditioning}

The present results indicate that, during active avoidance conditioning, the thalamus and the superior colliculus can both detect the CS that elicits the conditioned response. However, previous work has shown that, during pavlovian fear conditioning, the CS travels through the thalamus to evoke fear measured as freezing behavior. Thus, we tested the effects of somatosensory thalamus inactivation on freezing behavior in a pavlovian fear conditioning paradigm using a WCS. A group of rats $(n=17)$ were implanted with whisker pad stimulating electrodes to deliver the WCS, and some of these animals were also implanted with a guide cannula

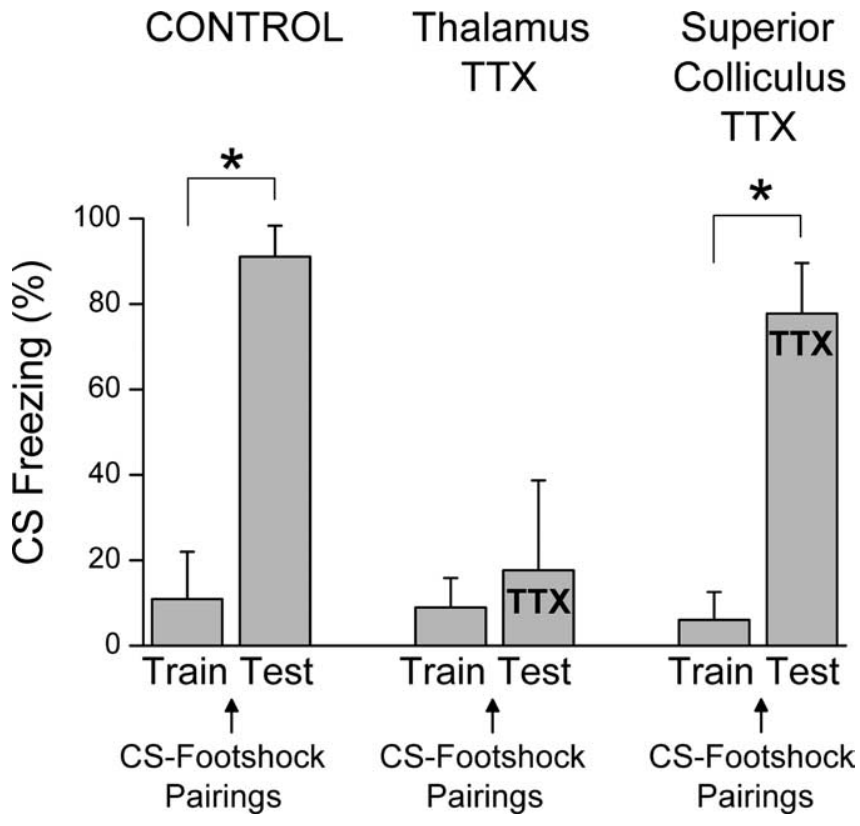

Figure 9. Effects of somatosensory thalamus or superior colliculus inactivation on WCS pavlovian fear conditioning. Animals were placed in a conditioning chamber on 2 consecutive days. On the training day, the amount of freezing was measured during the presentation of 10 WCSalone trials (150s). This was followed by 10 WCS-footshock pairing trials (marked by an arrow). On the test day ( $24 \mathrm{~h}$ later), the animals were divided in three groups ( $n=5-6$ per group): a control group, a thalamus TTX group, and a superior colliculus TTX group. The TTX groups received an infusion of TTX contralateral to the WCS before testing. The groups were placed in a different cage than on the training day, and the amount of freezing was again measured during the presentation of 10 WCS-alone trials. Note that TTX infusion in the somatosensory thalamus, but not in the superior colliculus, blocked freezing to the WCS. ${ }^{*} p<0.001$ versus training day.

in the somatosensory thalamus $(n=6)$ or in the superior colliculus $(n=5)$ contralateral to the WCS. After recovery from surgery, all of the animals were placed in a conditioning chamber on 2 consecutive days. On the first day (training), after a $5 \mathrm{~min}$ baseline period, 10 WCS-alone trials were presented (15 s WCS presentation per trial; see Materials and Methods). This was followed by 10 WCS-footshock pairing trials. On the second day (test), the animals with thalamic or superior colliculus cannulas received a TTX injection in those areas $(1 \mu \mathrm{l}, 10 \mu \mathrm{M})$, and all of the animals were placed in a different conditioning chamber than on day 1 . After a 5 min baseline period, 10 WCS-alone trials were presented. We measured the amount of freezing behavior during the baseline period ( $5 \mathrm{~min}$ ) and during the WCS trials (150 s) on the training and test days (Fig. 9). As a consequence of the WCSfootshock pairing, the amount of freezing during the $5 \mathrm{~min}$ baseline period did not change significantly between any of the groups or conditions (data not shown). However, the amount of freezing behavior to the WCS-alone trials increased significantly $(p<$ 0.001) on the test day compared with the training day in the control group of animals and in the animals infused with TTX in the superior colliculus, both of which have an intact somatosensory thalamus. However, animals that on the test day received a TTX infusion in the somatosensory thalamus contralateral to the WCS before the test session showed no significant change in freezing behavior compared with the training day. Thus, somatosensory thalamus inactivation blocked the ability of the somatosensory WCS to elicit a fear response (freezing). This is similar to previous studies that tested thalamic lesions and sensory stimuli for other sensory modalities (Tischler and Davis, 1983; LeDoux et 
al., 1984; Iwata et al., 1986; Shi and Davis, 2001). These results indicate that, in contrast to WCS detection during active avoidance conditioning, the WCS is only detected through the trigeminothalamic pathway (not through the trigeminotectal pathway) during pavlovian fear conditioning.

\section{Discussion}

Lesions of the somatosensory thalamus or superior colliculus do not impair detection of a WCS in an active avoidance task. However, unilateral disruption of both somatosensory thalamus and superior colliculus abolished the animals' ability to detect the WCS and perform the active avoidance behavior. These animals had no deficit in detecting an ACS, which supports the notion that the animals were selectively impaired in their ability to detect the WCS and had no other deficits in motor or cognitive functions required for the avoidance behavior. These results demonstrate that the trigeminothalamic and trigeminotectal pathways serve as alternative routes for somatosensory signal detection during avoidance behavior. However, the trigeminothalamic pathway is critically engaged in signal detection during pavlovian fear conditioning. Thus, even at very early stages of processing, the neural signals representing the CS are highly distributed in parallel and redundant sensory circuits, each of which can accomplish CS detection effectively and independently, but this depends on the conditioning paradigm involved.

It is not surprising that the trigeminothalamic pathway can detect the CS on its own during lesions of the superior colliculus, because cells in the thalamus and cortex have elaborate response properties and receptive fields that change as a function of behavioral state and neuromodulator influences (Poggio and Mountcastle, 1963; Livingstone and Hubel, 1981; Castro-Alamancos, 2002a,b; Bezdudnaya et al., 2006; Hirata et al., 2006). Moreover, although the activities of primary somatosensory cortex cells do not covary with successful sensory detection in monkeys (de Lafuente and Romo, 2005), cortical mechanisms are surely implicated in detection of somatosensory stimuli (Hyvarinen et al., 1968; Mountcastle et al., 1969; Romo and Salinas, 2003; de Lafuente and Romo, 2005). However, it was surprising that, during thalamic lesions, which block ascending inputs to cortex, the trigeminotectal pathway was capable of CS detection during active avoidance. The response properties of superior colliculus cells to whisker stimulation have been less intensely investigated than in the thalamus, but here we show that trigeminotectal responses are robust and, like trigeminothalamic responses, display rapid sensory adaptation. Moreover, superior colliculus cells have been reported to have quite large receptive fields (Stein and Dixon, 1979; Fujikado et al., 1981; Rhoades et al., 1983, 1987; McHaffie et al., 1989; Grunwerg and Krauthamer, 1990; Hemelt and Keller, 2007).

Indeed, although the trigeminothalamic and trigeminotectal pathways do not differ much in their individual abilities for CS detection, it is possible that they differ in more sophisticated CS discrimination abilities. Using active whisking, rats are capable of discriminating between rough surfaces, traversing gaps, and distinguishing shapes (Hutson and Masterton, 1986; Carvell and Simons, 1990; Guic-Robles et al., 1992; Brecht et al., 1997; Harvey et al., 2001; Kleinfeld et al., 2006). Surface discrimination and gap crossing behaviors are impaired by lesions of the somatosensory cortex (Hutson and Masterton, 1986; Guic-Robles et al., 1992), which suggests involvement of the trigeminothalamic pathway leading to cortex. Indeed, neural correlates of sensory discrimination are found in the somatosensory cortex (Hyvarinen et al., 1968; Mountcastle et al., 1969; Johnson and Hsiao, 1992; Romo and Salinas, 2003; Romo et al., 2003; Luna et al., 2005). However, cortical lesions can have unexpected effects. In the visual system, cats are virtually blind after lesions of the visual cortex, but this can be reversed by a lesion of the tectal commissure, a phenomenon called the "Sprague effect" (Sprague, 1966). The recovery caused by the tectal commissure lesion is attributable to elimination of an inhibitory input (Ciaramitaro et al., 1997; Jiang et al., 2003) from the substantia nigra contralateral to the visual cortex lesion onto the superior colliculus ipsilateral to the cortical lesion (Wallace et al., 1989, 1990). Thus, cats with visual cortex lesions and a tectal commissurotomy (i.e., using their superior colliculus to see) demonstrate good visually guided behavior, such as orienting toward and approaching food items presented to them, but are incapable of discriminating visual shapes (Sherman, 1977; Loop and Sherman, 1977). In our study, the lesions of the ascending forebrain pathway were done in the thalamus, which is not expected to produce a Sprague effect, and we found that animals can detect significant sensory signals, such as a WCS, using solely the trigeminotectal pathway.

The superior colliculus is well known to be involved in orienting responses to stimuli from a wide range of modalities, including somatosensory, auditory, and visual (Sprague and Meikle, 1965; Schneider, 1969; Meredith and Stein, 1985; Sparks, 1986; Dean et al., 1989; Stein and Meredith, 1993; Stein, 1998). Stimulation of the superior colliculus produces defensive behaviors, of which escape responses are particularly relevant to active avoidance conditioning (Bandler et al., 1985; Dean et al., 1988, 1989; Brandao et al., 1994, 2003). These behaviors occur via descending projections from the deep layers of the superior colliculus to motor and premotor centers located in the brainstem and spinal cord (Dean et al., 1988, 1989; Westby et al., 1990; Redgrave et al., 1993). In addition, behaviors such as target selection, object tracking, eye, head and body orientation, fear potentiation, and prepulse inhibition of the startle reflex are believed to be dependent on the superior colliculus for their expression (Tischler and Davis, 1983; Dean et al., 1989; Fendt et al., 2001). Our results indicate that the superior colliculus can serve as an early relay station for rapid detection of sensory signals that are behaviorally significant as a consequence of learning and require immediate action. In fact, in trained animals, the trigeminotectal sensory relay appears to be more efficient for avoidance than the trigeminothalamic relay because animals with thalamic lesions had faster avoidance latencies than animals with superior colliculus lesions.

Because both the sensory thalamus and superior colliculus appear to be alternative relays for CS detection during active avoidance behavior but not during pavlovian fear conditioning, an intriguing question is whether these two sensory relays lead to the same higher-order structure in which the CS and the unconditioned stimulus (footshock) become associated. Alternatively, the thalamic and colliculus relays may engage different neural systems capable of mediating the avoidance behavior. In pavlovian fear conditioning, that higher-order structure in which the CS and the footshock are associated is the amygdala (Davis, 1997; LeDoux, 2000; Maren, 2001; Fanselow and Poulos, 2005). However, in a form of fear conditioning called passive avoidance, the amygdala has been proposed (McGaugh et al., 1996; McGaugh, 2000) to have only a modulatory role (Wilensky et al., 2000; Kim and Jung, 2006). In rabbits, learning of discriminative avoidance behavior is dependent on the amygdala whereas performance is not (Poremba and Gabriel, 1997, 1999), and this also appears to be the case for active avoidance in rats (Roozendaal et al., 1993). Furthermore, different amygdala output nuclei have been shown to mediate learning of pavlovian fear conditioning and escape 
from fear conditioning, which is similar to active avoidance, whereas the central nucleus of the amygdala is critical for acquisition of pavlovian fear conditioning and the basal nucleus is critical for acquisition of escape from fear conditioning (Amorapanth et al., 2000). Thus, the engagement of different neural systems in different conditioning paradigms is a likely possibility. Moreover, a differential engagement of neural systems during acquisition versus performance is also likely. Although the present study focused on performance (i.e., trained animals), active avoidance learning (acquisition) may involve critically the sensory thalamus because, during acquisition, the amygdala may be involved in making the CS fearful through pavlovian fear conditioning. If this is the case, lesions of the somatosensory thalamus should block acquisition of active avoidance to a WCS. Future work will have to test this intriguing possibility. Another question relates to the role of the posterior intralaminar thalamus in active avoidance. This region receives ascending inputs from the superior colliculus (McHaffie et al., 2005) and is involved in rapid response selection during appetitive instrumental conditioning (Komura et al., 2005) and in the acquisition but not expression of pavlovian fear conditioning (Shi and Davis, 1999). Some of our thalamic lesions damaged this region without apparent effects on active avoidance performance. Because we did not study acquisition, additional work is needed to determine the putative role of this region during active avoidance behavior.

As reported previously by others, we found that lesions of the modality-specific (somatosensory) sensory thalamus related to the CS completely blocked pavlovian fear conditioning (Tischler and Davis, 1983; LeDoux et al., 1984, 1986; Iwata et al., 1986; Romanski and LeDoux, 1992; Campeau and Davis, 1995; Shi and Davis, 2001; Boatman and Kim, 2006), but these lesions did not block active avoidance conditioning to the same CS. This suggests that pavlovian and active avoidance paradigms engage different neural systems even from the earliest process of CS detection. Possibly, the superior colliculus is incapable of relaying the, arguably, more complex CS information in pavlovian conditioning. Alternatively, the superior colliculus may not have access to the high-order circuits involved in pavlovian fear conditioning (e.g., amygdala). It will be interesting to compare fear conditioning (active avoidance vs pavlovian) paradigms side-by-side to determine whether indeed they also engage different higherorder neural systems.

\section{References}

Amorapanth P, LeDoux JE, Nader K (2000) Different lateral amygdala outputs mediate reactions and actions elicited by a fear-arousing stimulus. Nat Neurosci 3:74-79.

Bandler R, Depaulis A, Vergnes M (1985) Identification of midbrain neurones mediating defensive behaviour in the rat by microinjections of excitatory amino acids. Behav Brain Res 15:107-119.

Bezdudnaya T, Cano M, Bereshpolova Y, Stoelzel CR, Alonso JM, Swadlow HA (2006) Thalamic burst mode and inattention in the awake LGNd. Neuron 49:421-432.

Blanchard RJ, Blanchard DC (1969a) Crouching as an index of fear. J Comp Physiol Psychol 67:370-375.

Blanchard RJ, Blanchard DC (1969b) Passive and active reactions to feareliciting stimuli. J Comp Physiol Psychol 68:129-135.

Boatman JA, Kim JJ (2006) A thalamo-cortico-amygdala pathway mediates auditory fear conditioning in the intact brain. Eur J Neurosci 24:894-900.

Bolles RC, Grossen NE (1970) Function of the CS in shuttle-box avoidance learning by rats. J Comp Physiol Psychol 70:165-169.

Bolles RC, Stokes LW, Younger MS (1966) Does CS termination reinforce avoidance behavior? J Comp Physiol Psychol 62:201-207.

Bouton ME (2007) Learning and behavior. Sunderland, MA: Sinauer.
Brandao ML, Cardoso SH, Melo LL, Motta V, Coimbra NC (1994) Neural substrate of defensive behavior in the midbrain tectum. Neurosci Biobehav Rev 18:339-346.

Brandao ML, Troncoso AC, Souza Silva MA, Huston JP (2003) The relevance of neuronal substrates of defense in the midbrain tectum to anxiety and stress: empirical and conceptual considerations. Eur J Pharmacol 463:225-233.

Brecht M, Preilowski B, Merzenich MM (1997) Functional architecture of the mystacial vibrissae. Behav Brain Res 84:81-97.

Bruce LL, McHaffie JG, Stein BE (1987) The organization of trigeminotectal and trigeminothalamic neurons in rodents: a double-labeling study with fluorescent dyes. J Comp Neurol 262:315-330.

Campeau S, Davis M (1995) Involvement of subcortical and cortical afferents to the lateral nucleus of the amygdala in fear conditioning measured with fear-potentiated startle in rats trained concurrently with auditory and visual conditioned stimuli. J Neurosci 15:2312-2327.

Carvell GE, Simons DJ (1990) Biometric analyses of vibrissal tactile discrimination in the rat. J Neurosci 10:2638-2648.

Castro-Alamancos MA (2002a) Different temporal processing of sensory inputs in the rat thalamus during quiescent and information processing states in vivo. J Physiol (Lond) 539:567-578.

Castro-Alamancos MA (2002b) Properties of primary sensory (lemniscal) synapses in the ventrobasal thalamus and the relay of high-frequency sensory inputs. J Neurophysiol 87:946-953.

Castro-Alamancos MA (2004a) Absence of rapid sensory adaptation in neocortex during information processing states. Neuron 41:455-464.

Castro-Alamancos MA (2004b) Dynamics of sensory thalamocortical synaptic networks during information processing states. Prog Neurobiol 74:213-247.

Castro-Alamancos MA, Oldford E (2002) Cortical sensory suppression during arousal is due to the activity-dependent depression of thalamocortical synapses. J Physiol (Lond) 541:319-331.

Chiaia NL, Rhoades RW, Bennett-Clarke CA, Fish SE, Killackey HP (1991) Thalamic processing of vibrissal information in the rat. I. Afferent input to the medial ventral posterior and posterior nuclei. J Comp Neurol 314:201-216.

Ciaramitaro VM, Todd WE, Rosenquist AC (1997) Disinhibition of the superior colliculus restores orienting to visual stimuli in the hemianopic field of the cat. J Comp Neurol 387:568-587.

Davis M (1997) Neurobiology of fear responses: the role of the amygdala. J Neuropsychiatry Clin Neurosci 9:382-402.

de Lafuente V, Romo R (2005) Neuronal correlates of subjective sensory experience. Nat Neurosci 8:1698-1703.

Dean P, Mitchell IJ, Redgrave P (1988) Responses resembling defensive behaviour produced by microinjection of glutamate into superior colliculus of rats. Neuroscience 24:501-510.

Dean P, Redgrave P, Westby GW (1989) Event or emergency? Two response systems in the mammalian superior colliculus. Trends Neurosci 12:137-147.

Fanselow MS (1980) Conditioned and unconditional components of postshock freezing. Pavlov J Biol Sci 15:177-182.

Fanselow MS, Poulos AM (2005) The neuroscience of mammalian associative learning. Annu Rev Psychol 56:207-234.

Feldman SG, Kruger L (1980) An axonal transport study of the ascending projection of medial lemniscal neurons in the rat. J Comp Neurol 192:427-454.

Fendt M, Li L, Yeomans JS (2001) Brain stem circuits mediating prepulse inhibition of the startle reflex. Psychopharmacology (Berl) 156:216-224.

Fujikado T, Fukuda Y, Iwama K (1981) Two pathways from the facial skin to the superior colliculus in the rat. Brain Res 212:131-135.

Grunwerg BS, Krauthamer GM (1990) Vibrissa-responsive neurons of the superior colliculus that project to the intralaminar thalamus of the rat. Neurosci Lett 111:23-27.

Guic-Robles E, Jenkins WM, Bravo H (1992) Vibrissal roughness discrimination is barrelcortex-dependent. Behav Brain Res 48:145-152.

Harvey MA, Bermejo R, Zeigler HP (2001) Discriminative whisking in the head-fixed rat: optoelectronic monitoring during tactile detection and discrimination tasks. Somatosens Mot Res 18:211-222.

Hemelt ME, Keller A (2007) Superior sensation: superior colliculus participation in rat vibrissa system. BMC Neurosci 8:12. 
Hirata A, Aguilar J, Castro-Alamancos MA (2006) Noradrenergic activation amplifies bottom-up and top-down signal-to-noise ratios in sensory thalamus. J Neurosci 26:4426-4436.

Huerta MF, Frankfurter A, Harting JK (1983) Studies of the principal sensory and spinal trigeminal nuclei of the rat: projections to the superior colliculus, inferior olive, and cerebellum. J Comp Neurol 220:147-167.

Hutson KA, Masterton RB (1986) The sensory contribution of a single vibrissa's cortical barrel. J Neurophysiol 56:1196-1223.

Hyvarinen J, Sakata H, Talbot WH, Mountcastle VB (1968) Neuronal coding by cortical cells of the frequency of oscillating peripheral stimuli. Science 162:1130-1132.

Iwata J, LeDoux JE, Meeley MP, Arneric S, Reis DJ (1986) Intrinsic neurons in the amygdaloid field projected to by the medial geniculate body mediate emotional responses conditioned to acoustic stimuli. Brain Res 383:195-214

Jiang H, Stein BE, McHaffie JG (2003) Opposing basal ganglia processes shape midbrain visuomotor activity bilaterally. Nature 423:982-986.

Johnson KO, Hsiao SS (1992) Neural mechanisms of tactual form and texture perception. Annu Rev Neurosci 15:227-250.

Killackey HP, Erzurumlu RS (1981) Trigeminal projections to the superior colliculus of the rat. J Comp Neurol 201:221-242.

Kim JJ, Jung MW (2006) Neural circuits and mechanisms involved in Pavlovian fear conditioning: a critical review. Neurosci Biobehav Rev 30:188-202.

Kleinfeld D, Ahissar E, Diamond ME (2006) Active sensation: insights from the rodent vibrissa sensorimotor system. Curr Opin Neurobiol 16:435-444.

Komura Y, Tamura R, Uwano T, Nishijo H, Ono T (2005) Auditory thalamus integrates visual inputs into behavioral gains. Nat Neurosci $8: 1203-1209$

LeDoux JE (2000) Emotion circuits in the brain. Annu Rev Neurosci 23:155-184.

LeDoux JE, Sakaguchi A, Reis DJ (1984) Subcortical efferent projections of the medial geniculate nucleus mediate emotional responses conditioned to acoustic stimuli. J Neurosci 4:683-698.

LeDoux JE, Sakaguchi A, Iwata J, Reis DJ (1986) Interruption of projections from the medial geniculate body to an archi-neostriatal field disrupts the classical conditioning of emotional responses to acoustic stimuli. Neuroscience 17:615-627.

Livingstone MS, Hubel DH (1981) Effects of sleep and arousal on the processing of visual information in the cat. Nature 291:554-561.

Loop MS, Sherman SM (1977) Visual discriminations of cats with cortical and tectal lesions. J Comp Neurol 174:79-88.

Luna R, Hernandez A, Brody CD, Romo R (2005) Neural codes for perceptual discrimination in primary somatosensory cortex. Nat Neurosci 8:1210-1219.

Maren S (2001) Neurobiology of Pavlovian fear conditioning. Annu Rev Neurosci 24:897-931.

McGaugh JL (2000) Memory-a century of consolidation. Science 287:248-251.

McGaugh JL, Cahill L, Roozendaal B (1996) Involvement of the amygdala in memory storage: interaction with other brain systems. Proc Natl Acad Sci USA 93:13508-13514.

McHaffie JG, Kao CQ, Stein BE (1989) Nociceptive neurons in rat superior colliculus: response properties, topography, and functional implications. J Neurophysiol 62:510-525.

McHaffie JG, Stanford TR, Stein BE, Coizet V, Redgrave P (2005) Subcortical loops through the basal ganglia. Trends Neurosci 28:401-407.

Meredith MA, Stein BE (1985) Descending efferents from the superior colliculus relay integrated multisensory information. Science 227:657-659.

Mineka S (1979) The role of fear in theories of avoidance learning, flooding, and extinction. Psychol Bull 86:985-1010.

Mountcastle VB, Talbot WH, Sakata H, Hyvarinen J (1969) Cortical neuronal mechanisms in flutter-vibration studied in unanesthetized monkeys. Neuronal periodicity and frequency discrimination. J Neurophysiol $32: 452-484$.

Mowrer OH (1960) Learning theory and behavior. New York: Wiley.

Poggio GF, Mountcastle VB (1963) The functional properties of ventrobasal thalamic neurons studied in unanesthetized monkeys. J Neurophysiol 26:775-806.
Poremba A, Gabriel M (1997) Amygdalar lesions block discriminative avoidance learning and cingulothalamic training-induced neuronal plasticity in rabbits. J Neurosci 17:5237-5244.

Poremba A, Gabriel M (1999) Amygdala neurons mediate acquisition but not maintenance of instrumental avoidance behavior in rabbits. J Neurosci 19:9635-9641.

Redgrave P, Gurney K (2006) The short-latency dopamine signal: a role in discovering novel actions? Nat Rev Neurosci 7:967-975.

Redgrave P, Westby GW, Dean P (1993) Functional architecture of rodent superior colliculus: relevance of multiple output channels. Prog Brain Res 95:69-77.

Rescorla RA, Solomon RL (1967) Two-process learning theory: Relationships between Pavlovian conditioning and instrumental learning. Psychol Rev 74:151-182.

Rhoades RW, Mooney RD, Jacquin MF (1983) Complex somatosensory receptive fields of cells in the deep laminae of the hamster's superior colliculus. J Neurosci 3:1342-1354.

Rhoades RW, Mooney RD, Klein BG, Jacquin MF, Szczepanik AM, Chiaia NL (1987) The structural and functional characteristics of tectospinal neurons in the golden hamster. J Comp Neurol 255:451-465.

Rhoades RW, Fish SE, Chiaia NL, Bennett-Clarke C, Mooney RD (1989) Organization of the projections from the trigeminal brainstem complex to the superior colliculus in the rat and hamster: anterograde tracing with Phaseolus vulgaris leucoagglutinin and intra-axonal injection. J Comp Neurol 289:641-656.

Rogan MT, Staubli UV, LeDoux JE (1997) Fear conditioning induces associative long-term potentiation in the amygdala. Nature 390:604-607.

Romanski LM, LeDoux JE (1992) Equipotentiality of thalamo-amygdala and thalamo-cortico-amygdala circuits in auditory fear conditioning. J Neurosci 12:4501-4509.

Romo R, Salinas E (2003) Flutter discrimination: neural codes, perception, memory and decision making. Nat Rev Neurosci 4:203-218.

Romo R, Hernandez A, Zainos A, Salinas E (2003) Correlated neuronal discharges that increase coding efficiency during perceptual discrimination. Neuron 38:649-657.

Roozendaal B, Koolhaas JM, Bohus B (1993) The central amygdala is involved in conditioning but not in retention of active and passive shock avoidance in male rats. Behav Neural Biol 59:143-149.

Schneider GE (1969) Two visual systems. Science 163:895-902.

Seligman MEP, Johnston JA (1973) A cognitive theory of avoidance learning. In: Contemporary approaches to conditioning and learning (McGuigan FJ, Lumsden DB, eds). New York: Wiley.

Sherman SM (1977) The effect of superior colliculus lesions upon the visual fields of cats with cortical ablations. J Comp Neurol 172:211-229.

Shi C, Davis M (1999) Pain pathways involved in fear conditioning measured with fear-potentiated startle: lesion studies. J Neurosci 19:420-430.

Shi C, Davis M (2001) Visual pathways involved in fear conditioning measured with fear-potentiated startle: behavioral and anatomic studies. J Neurosci 21:9844-9855.

Spacek J, Lieberman AR (1974) Ultrastructure and three-dimensional organization of synaptic glomeruli in rat somatosensory thalamus. J Anat 117:487-516.

Sparks DL (1986) Translation of sensory signals into commands for control of saccadic eye movements: role of primate superior colliculus. Physiol Rev 66:118-171.

Sprague JM (1966) Interaction of cortex and superior colliculus in mediation of visually guided behavior in the cat. Science 153:1544-1547.

Sprague JM, Meikle Jr TH (1965) The role of the superior colliculus in visually guided behavior. Exp Neurol 11:115-146.

Stein BE (1998) Neural mechanisms for synthesizing sensory information and producing adaptive behaviors. Exp Brain Res 123:124-135.

Stein BE, Dixon JP (1979) Properties of superior colliculus neurons in the golden hamster. J Comp Neurol 183:269-284.

Stein BE, Meredith MA (1993) The merging of the senses. Cambridge, MA: MIT.

Tischler MD, Davis M (1983) A visual pathway that mediates fearconditioned enhancement of acoustic startle. Brain Res 276:55-71.

Veazey RB, Severin CM (1982) Afferent projections to the deep mesencephalic nucleus in the rat. J Comp Neurol 204:134-150.

Veinante P, Deschenes M (1999) Single- and multi-whisker channels in the 
ascending projections from the principal trigeminal nucleus in the rat. J Neurosci 19:5085-5095.

Veinante P, Jacquin MF, Deschenes M (2000) Thalamic projections from the whisker-sensitive regions of the spinal trigeminal complex in the rat. J Comp Neurol 420:233-243.

Waite PME (2003) Trigeminal sensory system. In: The rat nervous system (Paxinos G, ed), pp 817-851. London: Elsevier.

Wallace SF, Rosenquist AC, Sprague JM (1989) Recovery from cortical blindness mediated by destruction of nontectotectal fibers in the commissure of the superior colliculus in the cat. J Comp Neurol 284: $429-450$.

Wallace SF, Rosenquist AC, Sprague JM (1990) Ibotenic acid lesions of the lateral substantia nigra restore visual orientation behavior in the hemianopic cat. J Comp Neurol 296:222-252.

Westby GW, Keay KA, Redgrave P, Dean P, Bannister M (1990) Output pathways from the rat superior colliculus mediating approach and avoidance have different sensory properties. Exp Brain Res 81: $626-638$

Wilensky AE, Schafe GE, LeDoux JE (2000) The amygdala modulates memory consolidation of fear-motivated inhibitory avoidance learning but not classical fear conditioning. J Neurosci 20:7059-7066.

Williams MN, Zahm DS, Jacquin MF (1994) Differential foci and synaptic organization of the principal and spinal trigeminal projections to the thalamus in the rat. Eur J Neurosci 6:429-453. 